\title{
An examination of land use impacts of flooding induced by sea level rise
}

\author{
Jie Song ${ }^{1}$, Xinyu $\mathrm{Fu}^{1}$, Yue Gu${ }^{1}$, Yujun Deng ${ }^{1}$, and Zhong-Ren Peng ${ }^{1,2,3}$ \\ ${ }^{1}$ Department of Urban and Regional Planning, University of Florida, Gainesville, Florida, FL 32611, USA \\ ${ }^{2}$ Center for Intelligent Transportation Systems and Unmanned Aerial Systems Applications, State Key \\ Laboratory of Ocean Engineering, School of Naval Architecture, Ocean and Civil Engineering, \\ Shanghai Jiao Tong University, Shanghai 200240, China \\ ${ }^{3}$ China Institute for Urban Governance, Shanghai Jiao Tong University, Shanghai 200240, China
}

Correspondence to: Zhong-Ren Peng (zpeng@ufl.edu)

Received: 9 May 2016 - Discussion started: 13 July 2016

Accepted: 14 February 2017 - Published: 7 March 2017

\begin{abstract}
Coastal regions become unprecedentedly vulnerable to coastal hazards that are associated with sea level rise. The purpose of this paper is therefore to simulate prospective urban exposure to changing sea levels. This article first applied the cellular-automaton-based SLEUTH model (Project Gigalopolis, 2016) to calibrate historical urban dynamics in Bay County, Florida (USA) - a region that is greatly threatened by rising sea levels. This paper estimated five urban growth parameters by multiple-calibration procedures that used different Monte Carlo iterations to account for modeling uncertainties. It then employed the calibrated model to predict three scenarios of urban growth up to 2080 - historical trend, urban sprawl, and compact development. We also assessed land use impacts of four policies: no regulations; flood mitigation plans based on the whole study region and on those areas that are prone to experience growth; and the protection of conservational lands. This study lastly overlaid projected urban areas in 2030 and 2080 with 500-year flooding maps that were developed under $0,0.2$, and $0.9 \mathrm{~m}$ sea level rise. The calibration results that a substantial number of built-up regions extend from established coastal settlements. The predictions suggest that total flooded area of new urbanized regions in 2080 would be more than 25 times that under the flood mitigation policy, if the urbanization progresses with few policy interventions. The joint model generates new knowledge in the domain between land use modeling and sea level rise. It contributes to coastal spatial planning by helping develop hazard mitigation schemes and can be employed in
\end{abstract}

other international communities that face combined pressure of urban growth and climate change.

\section{Introduction}

Coastal areas are the most intensively exploited places where urban expansion largely alters natural landscape. As landsea interfaces, however, these regions are featured by various conflicts between anthropogenic pressures and natural sustainability. Moreover, such conflicts have become exacerbated in recent years. While coastal zones increasingly attract population and investments, their communities are more aware of the intensified frequency of natural incidents and possible associations with climate change. It is evident that climate change partly contributes to intensified hurricanes and floods (Hsu, 2014), rising sea level (IPCC, 2013), and other coastal hazards. Moreover, sea level rise (SLR) may worsen coastal flooding, land submergence, and saltwater intrusion (Nicholls and Cazenave, 2010). According to the fifth report published by the Intergovernmental Panel on Climate Change (IPCC) in 2013, approximate $70 \%$ coastlines will experience rising sea levels by 2100 . Nonetheless, developers, business owners, and other stakeholders will still continue to compete for limited coastal resources, and the competition has been even more intense. Developers expedite new real estate projects, local governments offer appealing incentives to attract new infrastructure investments, and companies extensively extract oil and natural gas in offshore 
regions (Felsenstein and Lichter, 2014). Since coastal zones are both battlegrounds of conflicting interests and vulnerable low-lying places, coordinating land uses, hazard mitigation, and different interests has become everlastingly important. Such coordination, therefore, calls for effective tools to inform coastal management plans. Moreover, spatial planning plays a pivotal role in these schemes, which can be guided by land use/land cover changes (LULCC).

Various techniques can help detect LULCC patterns. The class of cellular automaton (CA) models receive wide attention around the world due to their simplicity and effectiveness in capturing complex urban dynamics (Akın et al., 2014). The operationalization of CA in modeling urban phenomena was first introduced by Clarke et al. (1997) who designed the prototype of SLEUTH - a CA-based urban simulation program. In their model, each cell had a state which updated at consecutive time points according to predefined transitional rules. These rules integrated the current condition of a cell, its neighbors, and environmental constraints. Numerous software packages have developed since the introduction of CA. Santé et al. (2010) evaluated 33 CA models and concluded that the SLEUTH gained more popularity than the other alternatives. The SLEUTH has been adopted by urban researchers all over the world since 2000 (Project Gigalopolis, 2016). Its popularity is partly due to free availability, user-friendliness, well-developed manuals, and a support forum. An elegant feature of the SLEUTH is the application of excluded layers. These layers denote different scenarios in a calibration procedure so as to exemplify how policies influence the expansion of built-up regions (Akın et al., 2014). Recently, SLEUTH was improved by the incorporation of external information in excluded layers. Rienow and Goetzke (2015) used the support vector machine to enhance SLEUTH's predictive power by developing probability-based excluded layers. Likewise, Sakieh et al. (2015) applied a multi-criterion evaluation method to generate suitability-based policy layers.

Scenario-based SLEUTH and other CA models can also forecast future land use, based on historical urban expansion information. By applying a constrained CA model, Hansen (2010) simulated future land conditions under different emission scenarios developed by the IPCC (2013). The author concluded that significant areas in Aalborg would be increasingly exposed to future flooding hazards. Hansen (2010) further suggested that more aggressive strategies, such as population relocation and managed retreat, may be evaluated in future simulations. Similarly, Sekovski et al. (2015) assessed the impacts of coastal flooding upon urban growth using SLEUTH. Inouye et al. (2015) applied a comparative approach to validate the importance of zoning in land use simulations. By applying a CA package (Dynamic EGO), they stated that the developments in ecologicaleconomic zones heightened the vulnerability to land sliding, SLR, and other coastal hazards. Their results greatly benefit the formulation of relocation, planned retreat, and other adaptation strategies. More specifically, researchers also highlighted the importance of zoning in SLEUTH applications. Akın et al. (2014) used future zoning maps as excluded layers and evaluated the accuracy of hindcastingbased calibration. Onsted and Chowdhury (2014) employed a historical zoning map in their SLEUTH model and suggested that land use planning strongly influenced urban growth in Florida.

While the majority of SLEUTH applications focused on different urban forms (e.g., urban sprawl), their exposure to flooding received less attention. To the best of our knowledge, only two studies (Garcia and Loáiciga, 2014; Sekovski et al., 2015) attempted to couple land use predictions with marine flooding maps using SLEUTH. The combination of SLEUTH simulations and flooding hazard maps, however, should be prioritized to enhance spatial management (Onsted and Chowdhury, 2014). Therefore, this study aims to evaluate the extent to which SLR-induced flooding will threaten different urban growth patterns using SLEUTH Urban Growth Model. Specifically, two research questions of this study are as follows:

1. How does different urban growth patterns affect coastal vulnerability to SLR-induced flooding?

2. Will zoning and flood mitigation plans help steer prospective developments away from low-lying regions?

This paper is organized as follows. Section 2 describes our study area and why this region was selected as a case study. Following this, Sect. 3 illustrates an overall framework, describes data inputs, and outlines major steps for the calibration and prediction of urban growth in the study area as well as the development of SLR-induced flooding maps. In Sect. 4 we present the calibration coefficients and discuss forecasting outcomes that were overlaid with flooding maps. Finally, Sect. 5 offers a brief conclusion and provides the outlook for future research.

\section{Study area}

\subsection{Background}

This work selected Bay County in Northwest Florida (USA) as a primary case study region. Bay County and its adjacent areas (Washington and Walton counties) were used to prove our hypotheses based on two considerations: high exposure to coastal hazards and SLR that are experienced in the majority of worldwide coastal zones and data availability for modeling. Bay County has a long shoreline along the Gulf Coast (Fig. 1). It is representative in the context of climate change, since it faces unprecedented and accelerated threats from storm surges, hurricanes, and projected sea level variations. Similar exposure has been demonstrated in the European coastline (Vousdoukas et al., 2016), western US coast 
(Ludy and Kondolf, 2012), southern Vietnam (Apel et al., 2016), and many other coastal megacities around the world.

Specifically, Bay County's exposure to marine disasters is pronounced. This coastal county has been hit by 17 hurricanes since 1877 (Hurricanecity, 2015). Among these incidences, Hurricane Eloise in 1975 led to enormous damages in structures, seawalls, and patios - equivalent to up to EUR 23.1 million (Shows, 1978). Moreover, land development patterns render this region extremely susceptible to hurricanes and SLR. A considerable number of structures encroached upon seafront areas in Panama City due to the absence of land use regulations in the past (Bay County Online, 2016). Primary industrial sectors in Bay Country, as in other coastal communities, are largely susceptible to coastal hazards as well. Bay County relies on tourism-related industries which are deemed vulnerable to rising sea levels (Ebert et al., 2016). Bay County has 10222 firms, of which approximate $90 \%$ are small businesses. Unfortunately, small companies have insufficient resources to cope with storm surge, flooding, and other environmental disasters (Runyan, 2006; Song et al., 2016).

The second rationale for choosing Bay Country is the data availability for modeling. This work used an integrative framework, requiring high-quality data sets regarding land cover and hydrological factors. Land use data can be obtained from different sources. However, generating SLRinduced flooding maps requires sufficient observations at local and global levels, hurricane records, and many other marine and meteorological variables - these are available for the study area. Based on these considerations, we chose Bay County to explore the research questions.

\subsection{Urban change and zoning}

Figure 2 displays that urban extent expanded primarily in the southern part of Bay County and largely conformed to historical trends. A multitude of residential developments occur in Panama City and shoreline regions. Additionally, many areas in the north are zoned for residential uses. This information suggests that local governments and planning agencies have taken measures to encourage spatially diverse developments. There exists, however, an apparent discrepancy between zoning and urban growth: a substantial number of urban areas have appeared in Fountain and Youngstown. Nonetheless, the zoning unclearly reflects this pattern, and only some areas are designated for the residential land use in the two towns. This inconsistency implies that planners need a comprehensive understanding of past land use changes to better design zoning schemes.

\section{Methodological approach}

Figure 3 displays the overall research framework. Specifically, the technical road map was organized into four phases:
(1) data collection and preprocessing, (2) the calibration in the SLEUTH environment, (3) the simulations of urban growth up to 2080 under the combined scenarios of different urban growth patterns and various excluded layers, and (4) the comparison of future urban areas and 500-year flooding maps that were induced by SLR. The framework has two major tasks: the SLEUTH Urban Growth Model and SLRinduced flooding maps, as will be discussed in the following sections.

\subsection{Rationale for model selection}

We applied SLEUTH as a general modeling architecture based on the following reasons. First, CA models are advantageous over other counterparts due to their spatial explicitness, flexible transitional rules, compatibility with large data sets (Wagner, 1997), and easy integration with ArcGIS ${ }^{\circledR}$ (Santé et al., 2010). Second, SLEUTH only relies on five inputs: urban, transportation, slope, hillshade, and exclusion. Third, SLEUTH employs excluded layers where a cell value of zero represents an attracting point for development, and 100 or higher reflects that urbanization is strictly prohibited. Such a functionality makes SLEUTH an excellent platform for scenario-based studies (Leão et al., 2004). Finally, its calibration process applies a "brute force" approach and is scientifically sound for regional studies (Onsted and Clarke, 2011).

\subsection{An introduction to SLEUTH}

\subsubsection{Background}

SLEUTH is a packed C-language-based source code that was developed by K. C. Clarke at the Department of Geography, University of California Santa Barbara. The source code is freely available through its official website called "Project Gigalopolis" (http://www.ncgia.ucsb.edu/projects/gig/index. html). SLEUTH has two modules: the Urban Growth Model and the Land Cover Deltatron Model. The Urban Growth Model mainly focuses on urban/non-urban dynamics and is thus a primary focus of this work.

\subsubsection{SLEUTH workflow}

SLEUTH is a scale-independent CA model that updates the binary state of each cell per growth cycle. A growth cycle is 1 year and determined by four rules: spontaneous growth, new spreading centers, edge (organic) growth, and roadinfluenced growth (Clarke et al., 1997). These transitional rules are controlled by one or more of the five parameters: dispersion, breed, spread, road gravity, and slope (Project Gigalopolis, 2016). Each parameter, with a value range of 1 to 100 , is dimensionless and can be compared regarding their contributions to overall growth. Specifically, the dispersion factor determines the probability by which a cell will be randomly selected for urbanization (Silva and Clarke, 2002). 


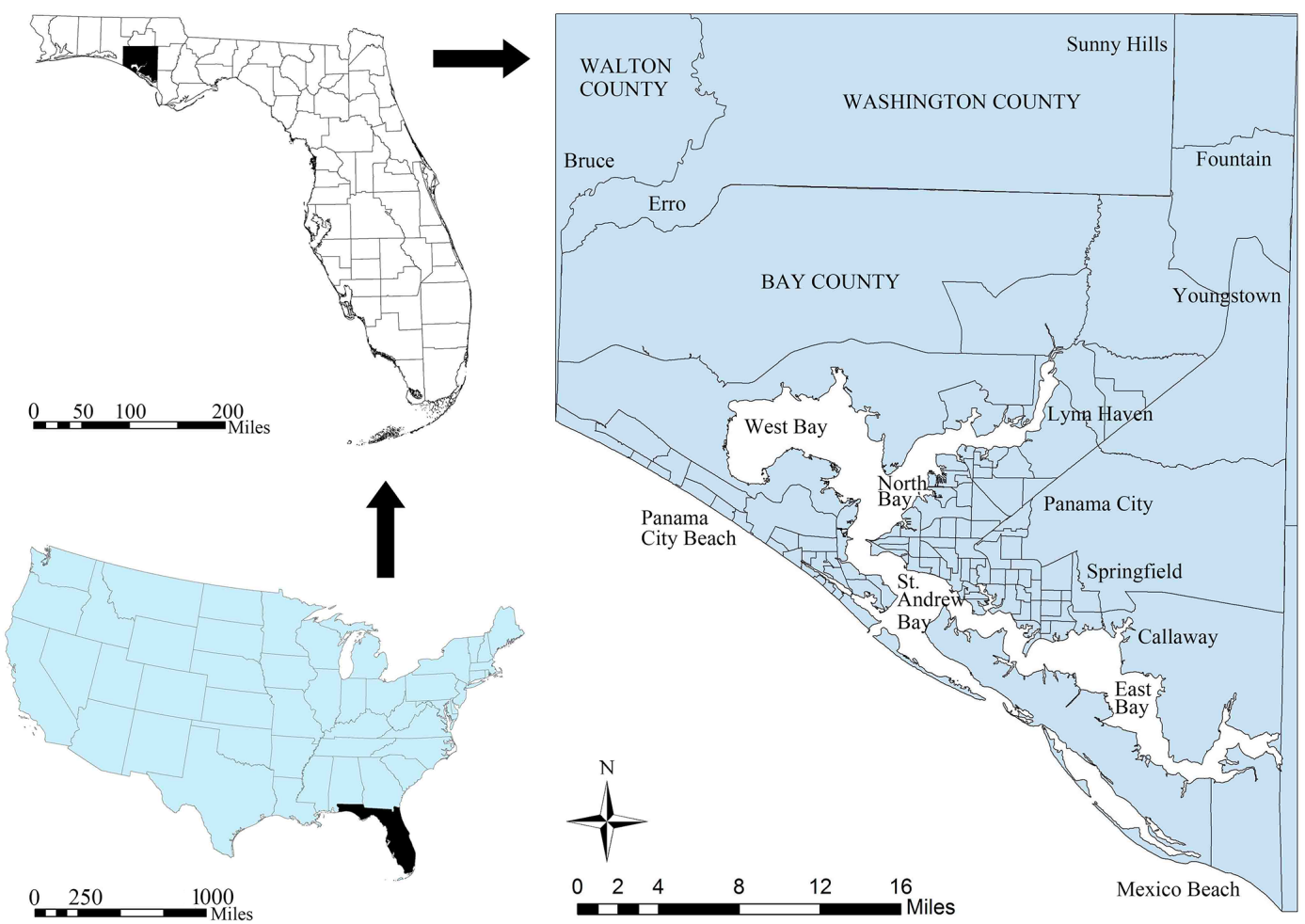

Figure 1. The study area.
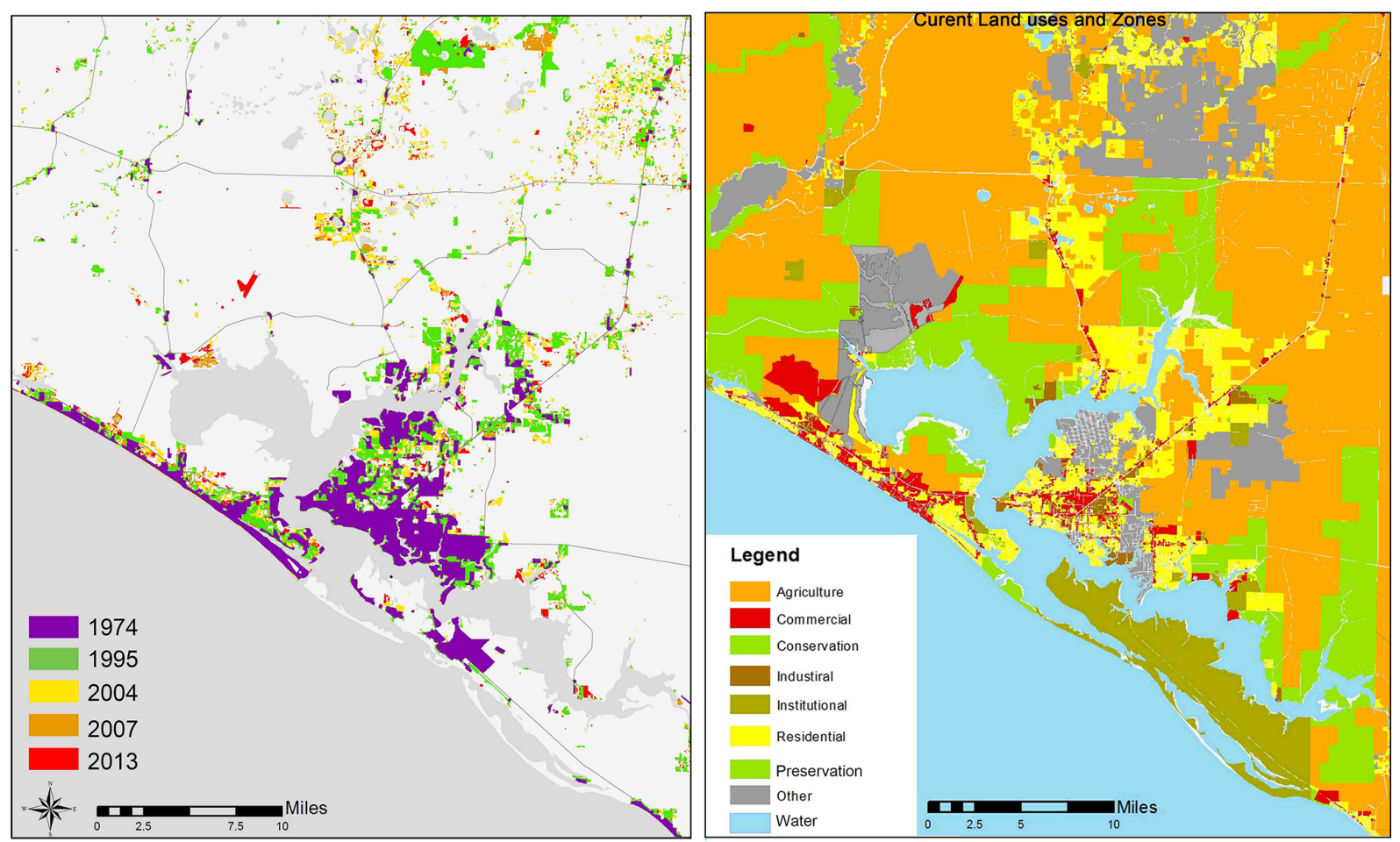

Figure 2. Historical urban changes (left) and current land uses and zones (right) for the study area. 


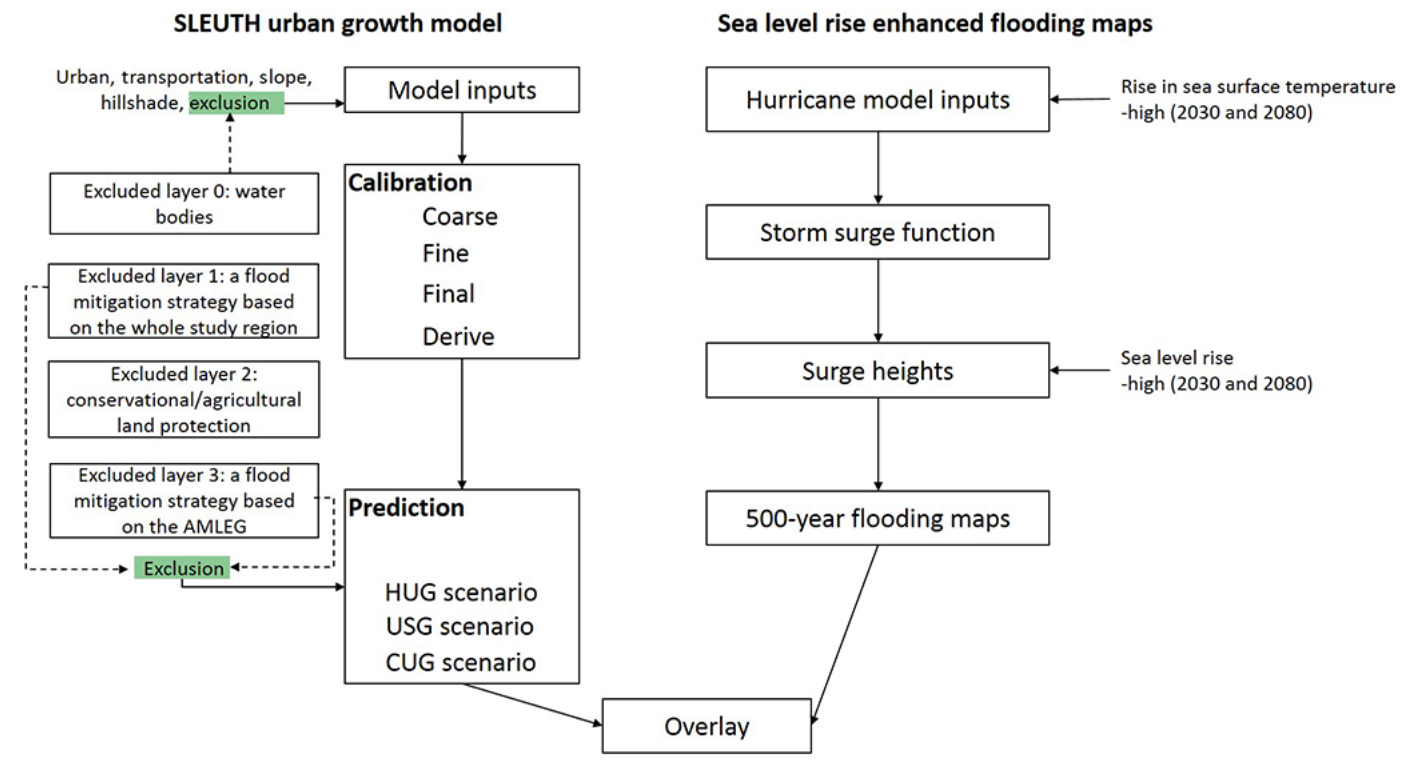

Figure 3. Overall study framework. HUG is historical urban growth; USG is urban sprawl growth; CUG is compact development; and AMLEG denotes areas more likely to experience growth.

The breed factor determines the likelihood by which a new urban cluster will start its growth cycles (Berberoğlu et al., 2016). The spread factor controls how likely outward growth will develop near an existing settlement. The road gravity factor demonstrates the influence of road systems upon land use by attracting new developments that are within a certain distance of a road (Silva and Clarke, 2002). Finally, the slope factor calculates how likely a cell with a steeper slope will be urbanized (Rafiee et al., 2009). Table 1 summarizes the relationships between transitional rules and five parameters.

The main workflow of a SLEUTH application includes input compilations, a calibration process based on actual urban growth, and predictions. The Urban Growth Model requires at least four maps of different dates which show obvious urban changes. Two road networks of different periods and one percentage-slope map are additional date sets. An optional hillshade map is used to improve visualization performance. The goal of the calibration is to select a combination of the parameters that best replicate historical urban changes. This process, however, is enormously time-consuming if modelers assess all combinations - up to 10 billion. Therefore, SLEUTH applies a four-stage calibration process (coarse, fine, final, and derive) to reduce computational time. Finally, the predictions with 100 Monte Carlo (MC) runs are conducted using the best-fit parameters.

\subsection{Data description for the Urban Growth Model}

Table 2 displays detailed information regarding all data sets required by the Urban Growth Model. The land use data were obtained from the Florida Geographic Data Library (FGDL) and included five remotely sensed images in 1974,
1995, 2004, 2007, and 2013. These data sets were categorized into nine level-one land cover classes, among which the built-up land was coded as one, according to the Florida land use, cover, and forms classification system published by the Florida Department of Transportation (1999). Flooding hazard and zoning information were also collected to create excluded layers. Two flood insurance rate maps (FIRM), developed by the US Federal Emergency Management Agency, were downloaded from the FGDL. Current zoning map and the comprehensive plan for the study area were obtained from the online GIS websites of Bay and Washington counties. The zoning map specified the degree to which different land uses were allowed for urban developments. According to the Bay County Comprehensive Plan (2009 to 2020), the zoning regulations are shown as follows:

- developments were not allowed in the zone of conservation (for the preservation purpose), and impervious areas must be no more than $5 \%$;

- in the area of conservation (for the habitation purpose), impervious surface must be no more than $50 \%$;

- in the zone of conservation (for the recreation purpose), impervious coverage must be no more than $10 \%$; and

- in the zones of agriculture for the timberland and other general purposes, impervious areas must be no more than 10 and $25 \%$ respectively. 
Table 1. The relationships among a growth cycle, transitional steps, and controlling factors (Clarke et al., 1997).

\begin{tabular}{llll}
\hline Growth cycle & Transitional steps & Controlling factors & Description \\
\hline $1-1$ & $\begin{array}{l}\text { Spontaneous growth } \\
\text { New spreading centers }\end{array}$ & $\begin{array}{l}\text { Dispersion } \\
\text { Breed }\end{array}$ & $\begin{array}{l}\text { Random urbanization of cells } \\
\text { Outward growth of new settlements formed } \\
\text { in the spontaneous growth stage }\end{array}$ \\
$1-2$ & $\begin{array}{l}\text { Edge growth } \\
\text { Road-influenced growth }\end{array}$ & $\begin{array}{l}\text { Spread and slope } \\
\text { Road gravity, dispersion, } \\
\text { breed, and slope }\end{array}$ & $\begin{array}{l}\text { Outward growth of current settlements } \\
\text { Growth of new settlements within a distance } \\
\text { of existing transportation networks }\end{array}$ \\
\hline
\end{tabular}

Table 2. The sources and descriptions of data sets used for the Urban Growth Model.

\begin{tabular}{llll}
\hline Data type & Year & Spatial resolution & Description and source \\
\hline Urban extent & 1974 & Vector files & Land use/cover maps from Florida Geographic Data Library \\
& 2995 & & \\
& 2004 & & \\
& 2007 & & \\
Transportation network & 2007 & Vector files & TIGER/Line_Shapefiles and TIGER/Line_Files (US Census Bureau, 2016) \\
Slope & 2013 & & \\
& - & $30 \times 30 \mathrm{~m}$ & Converted from National Elevation Datasets of Geospatial Data \\
Hillshade & & & Gateway from US Natural Resources Conservation Service \\
Exclusion & 1996 & Vector files & Flood insurance rate maps from Florida Geographic Data Library \\
& 2015 & & \\
& 2016 & Vector files & Land uses and zones from Bay County GIS online \\
\hline
\end{tabular}

\subsection{Urban Growth Model}

\subsubsection{Land-use/cover-related layers}

All input data were processed in $\operatorname{ArcGIS}^{\circledR}$ 10.3. Five land use maps in the vector format were converted into raster files using the nearest neighborhood method. Figure 4 shows urban changes in Bay County from 1974 to 2013. Only two most recent road-network maps were used due to data limitations. Because local roads may have a very limited influence upon urban growth, only main arteries were extracted from original line files according to the MAF/TIGER Feature Class Code. These polylines were then converted into raster files using the nearest neighbor resampling method. The slope and hillshade maps, collected from the National Elevation Dataset, were finally generated using the spatial analyst tool.

\subsubsection{The creation of E1 excluded layer}

An excluded layer reflects the urbanization probabilities of cells. Its cell values range from 0 (unaffected) to 100 (entirely excluded) (Akın et al., 2014). Onsted and Clarke (2012) recommended that the calibration and prediction stages utilize different excluded layers. The excluded layer for the calibration is suggested to be at minimal restrictions to obtain more precise results of urban growth, according to Akın et al. (2014). Hence, this layer (E0) only covers water bodies where urban developments are unrealistic (Fig. 4). For the prediction phase, however, three layers were applied to represent flood mitigation based the whole region (E1), conservational/agricultural land protection (E2), and flood mitigation based on the areas more likely to experience growth (AMLEG) (E3).

The E1 attempted to assess how likely urban growth appeared in the special flood hazard area (SFHA) which may be inundated by 100-year floods. Landowners must purchase mandatory flood insurance in these areas. Increasing construction costs in high-risk regions may partly inhibit vulnerable urban growth. Therefore, the E1 could represent a scenario which prohibits land developments in floodplains.

Weights in the E1 layer were determined according to the approach which Onsted et al. (2014) used to reduce the errors of randomly assigned values. To avoid arbitrarily assigning values to excluded layers, the authors elegantly used historical zoning maps to calculate the weights. Their method bases on annual growth rates whereby new urban developments appear in different zones. This method has a great potential to become a general rule in future SLEUTH applications. However, it assumes the annual rate remains unchanged over time. Therefore, concerns may arise if a study area experiences nonlinear growing rates over a period, which should be addressed in future studies. 

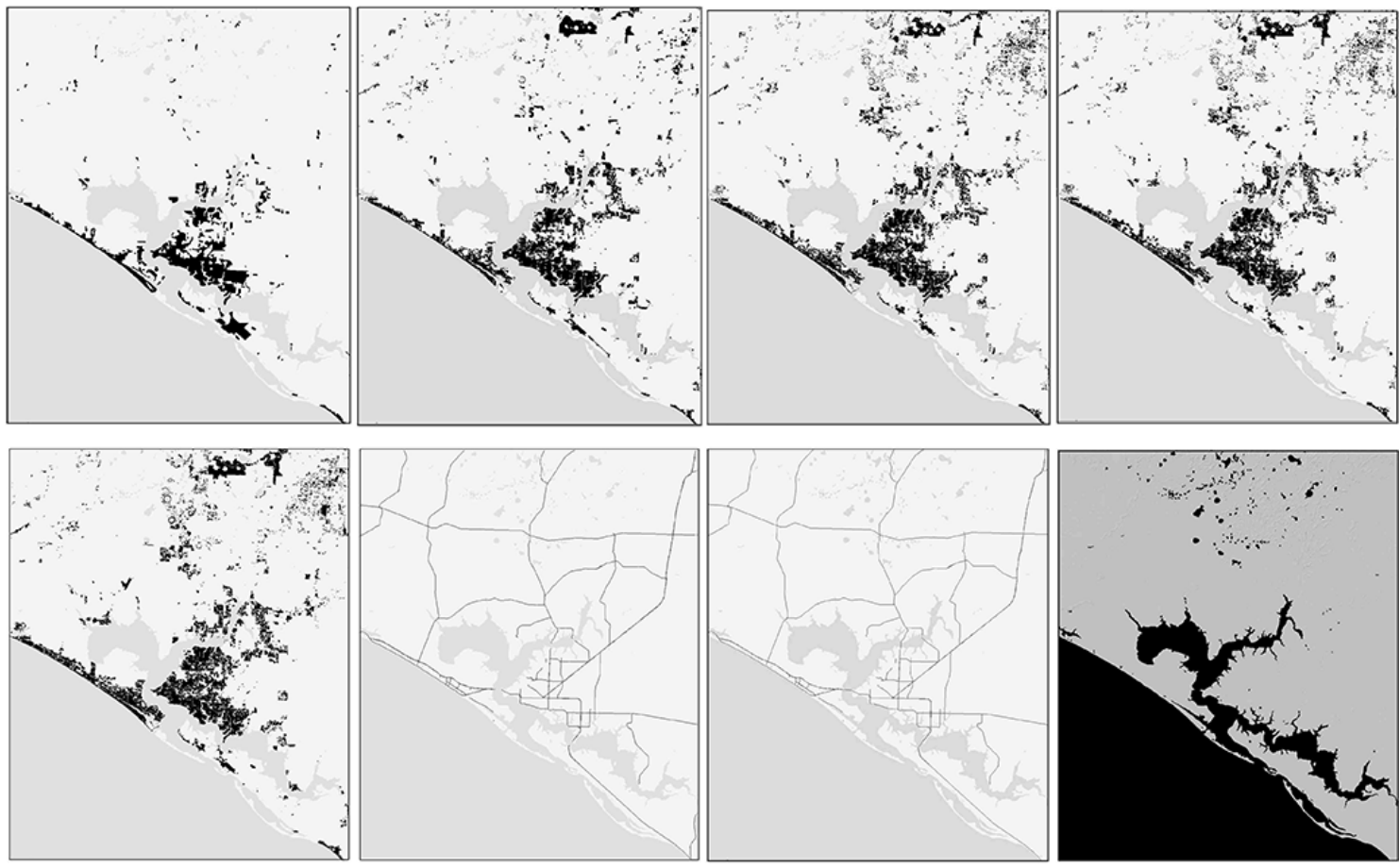

Water Urban
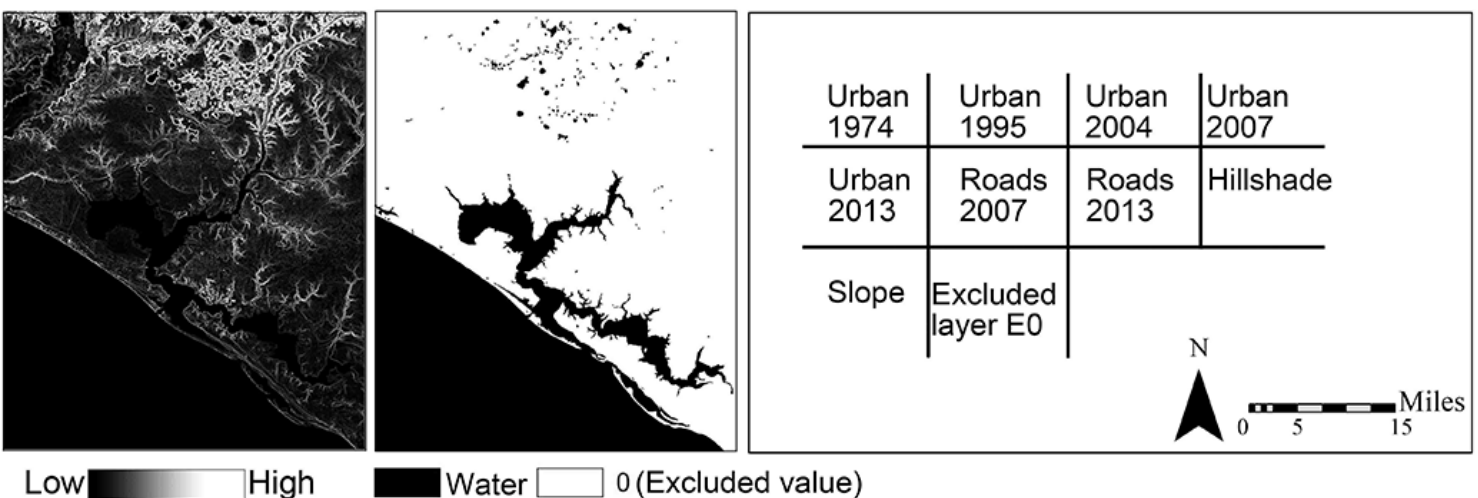

Figure 4. Land-use-related layers, transportation networks, topographic maps, and the historical excluded layer (E0) for model calibration. For the excluded layer, the higher value represents higher resistance to urban growth. The values range from 0 to 100 .

To retrieve past growth information, we selected the 1996 FIRM as a reference layer and calculated the area of SFHA and non-SFHA zones as well as the number of new urban areas from 1995 to 2013 in these zones respectively.

Next, the annual rate of urban growth in each zone was determined by Eq. (1):

$g_{n}=1-\left(\left(1-\left(\frac{G_{n}}{Z_{n}}\right)\right)^{\left(\frac{1}{T}\right)}\right)$,

where $G_{n}$ is the total actual urban growth in zone $n$ ( 1 is the SFHA and 2 is the non-SFHA zone) from 1995 to $2013, Z_{n}$ is total area of zone $n$ according to the 1996 FIRM, and $T$ is the number of years, i.e., 18 .
The growth rates were used to generate the excluded value in the SFHA zone by Eq. (2):

$E_{\mathrm{SFHA}}=100\left(1-\left(\frac{g_{1}}{g_{2}}\right)\right)$

where $g_{1}$ and $g_{2}$ denote the growth rates in the SFHA and non-SFHA zones respectively. Table 3 indicates that the growth rate in low-risk areas was approximately 3 times that in the SFHA zone, suggesting that mandatory flood insurance constrained urban expansion in flood-prone regions. Finally, the E1 layer was created based on the 2015 FIRM and represented a growth management that aims at mitigating flood risks (Fig. 5). 
Table 3. The development of excluded values for the E1 scenario (based on the whole study area).

\begin{tabular}{lrrrr}
\hline Zones & $\begin{array}{r}\text { New growth from } \\
1995 \text { to } 2013 \\
\text { (ha) }\end{array}$ & $\begin{array}{r}\text { Total } \\
\text { area } \\
\text { (ha) }\end{array}$ & $\begin{array}{r}\text { Growth } \\
\text { rate } \\
(\% \circ)\end{array}$ & $\begin{array}{r}\text { Excluded } \\
\text { value }\end{array}$ \\
\hline Special flood hazard area & 665 & 92054 & 0.4 & 68 \\
Non-SFHA & 4901 & 216095 & 1.3 & 0 \\
Water bodies & - & - & - & 100 \\
\hline
\end{tabular}

\subsubsection{The creation of E2 excluded layer}

The 2020 Bay County Comprehensive Plan was published in 2009 and represented the most recent managed growth option for the study area. Hence, excluded values in the E2 layer were weighted according to this plan and modified based on the work of Akın et al. (2014). Specifically, a cell value of 100 was assigned to water bodies, 95 to the conservation/preservation zones, 50 to the conservation/recreation and agriculture/timberland areas, 25 to the other agricultural areas and conservation/habitation zones, and 0 to all other areas (Fig. 6).

\subsubsection{The creation of E3 excluded layer}

Most SLEUTH modelers apply the abovementioned methods to develop excluded layers. However, such approaches may be deficient since these treat the whole study area homogeneously. Realistically, urban growth involves heterogeneous changes across the study area. For instance, new residential developments largely extend from existing settlements that may only cover a small area within a city boundary. Thus, Onsted and Chowdhury (2014) developed a procedure that corrects the growth rates in the AMLEG. The authors concluded that the AMLEG technique produced more accurate results than the other methods: arbitrary guessing and the calculation based on the whole study area. Therefore, the AMLEG approach was applied based on the E1 scenario (flood mitigation). Specifically, SLEUTH was first run in a prediction mode with $100 \mathrm{MC}$ times for the period of 1995 to 2013. All five growth coefficients were set as 100, and the cells with an urbanization probability of $50 \%$ or more were considered in the AMLEG (Fig. 7). Second, excluded values in the E3 excluded layer were recalculated using the Eqs. (1) and (2), based on the AMLEG effects (Table 4). Finally, the E3 layer was created based on the 2015 FIRM (Fig. 8).

Figure 7 shows the coastal areas with high-urbanization potentials. The rudimentary simulation of urban growth from 1995 to 2013 justifies the heterogeneous evolution of urban landscape within the whole study region. The excluded value (27) (Table 4) of the SFHA zone is considerably less than that (68) in the E1 excluded layer (Table 3). Such a decrease was also discovered by Onsted and Chowdhury (2014). Also, this finding indicates that substantial urban growth occurs in flooding-prone areas if we considered the AMLEG ef-
Table 4. The growth rates and excluded values for the E3 layer under the effects of AMLEG.

\begin{tabular}{lrrrr}
\hline Zones & $\begin{array}{r}\text { New growth from } \\
1995 \text { to } 2013 \\
\text { (ha) }\end{array}$ & $\begin{array}{r}\text { Total } \\
\text { area } \\
\text { (ha) }\end{array}$ & $\begin{array}{r}\text { Growth } \\
\text { rate } \\
(\%)\end{array}$ & $\begin{array}{r}\text { Excluded } \\
\text { value }\end{array}$ \\
\hline AMLEG & 140 & 513 & - & - \\
SFHA & 22 & 98 & 1.4 & 27 \\
Non-SFHA & 118 & 415 & 1.8 & 0 \\
\hline
\end{tabular}

fects. This phenomenon is intuitively reasonable since existing coastal regions are both low-lying places and developmental attractors.

All preprocessed raster files, including land use maps and four excluded layers, were eventually resampled at a spatial resolution of $30 \mathrm{~m} \times 30 \mathrm{~m}$, which is adequately high since the resolutions of most SLEUTH applications are in the range of 10-100 m (Akın et al., 2014). These raster data with 1972 rows $\times 2383$ columns were then exported as grayscale GIF images and imported into the SLEUTH program.

\subsubsection{Model calibration}

As mentioned, urban growth parameters were calibrated based on the "brute force" technique where analysts follow four calibration stages - coarse, fine, final, and derive. Increasingly higher image resolutions were typically used from the coarse to final calibrations for computational efficiency (Akın et al., 2014; Chakraborty et al., 2015; Rafiee et al., 2009). However, different resolutions may be problematic and lead to a biased estimation of growth patterns (Dietzel and Clarke, 2007). Thus, the consistent resolution of $30 \times 30 \mathrm{~m}$ was employed during the entire calibration process.

In each calibration phase, several MC iterations were simulated to account for the uncertainty associated with parameter estimations (Project Gigalopolis, 2016). A general strategy of identifying the "best-fit" parameters is to shrink the range of parameters during each phase. While increasing the number of MC iterations can slightly enhance accuracy, the rise in calculation time is extremely pronounced. To balance model fit and efficiency, SLEUTH developers and users experimented in different study areas and developed experiential numbers of MC runs during different steps: 4-5 (coarse); 


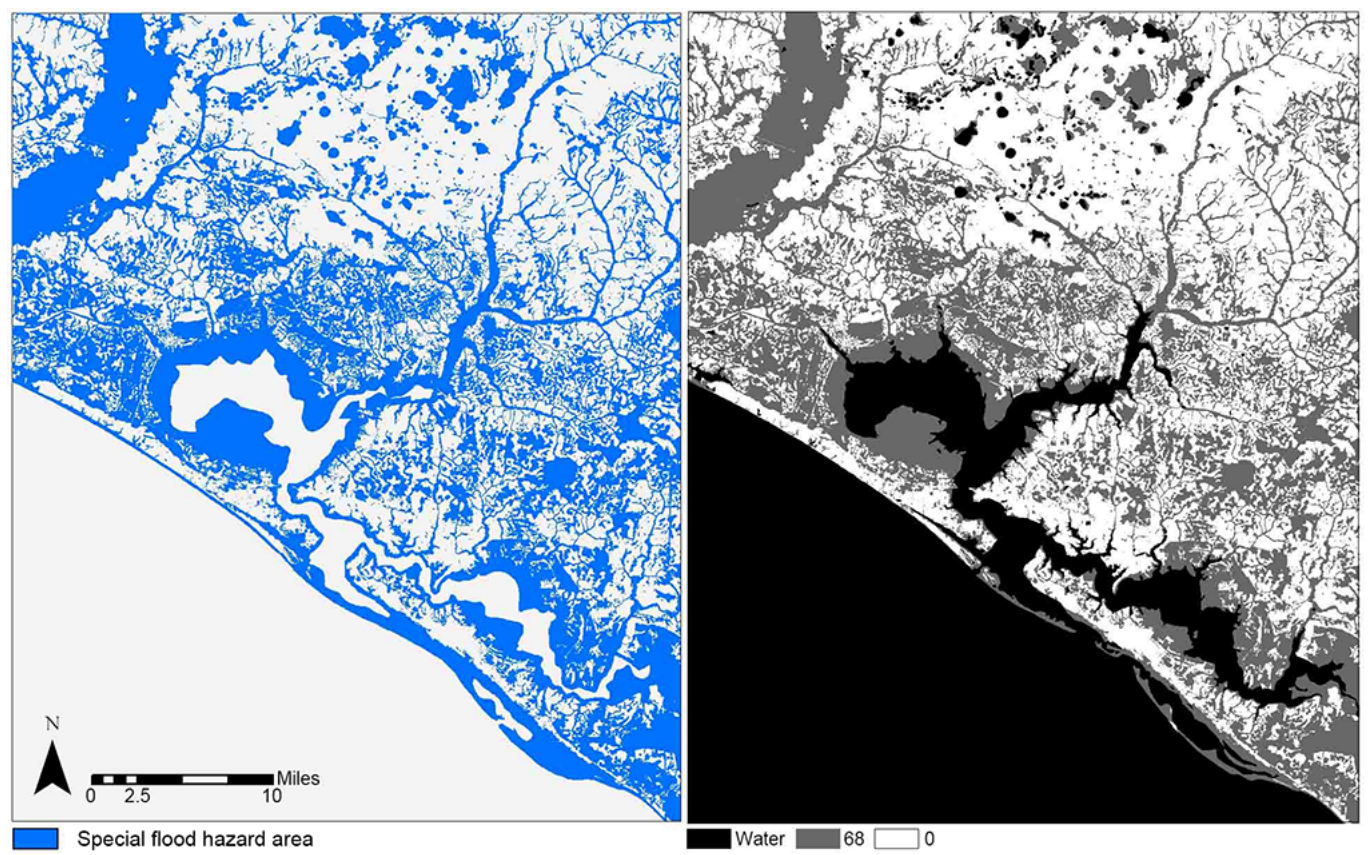

Figure 5. Special flood hazard area in 2015 (left) and the E1 excluded layer (right) (based on the whole study area). For the excluded layer, the higher value represents higher resistance to urban growth. The value ranges from 0 to 100 .

7-8 (fine); 8-10 (final); and 100 or greater (derive) (Project Gigalopolis, 2016). Hence, this work utilized 4, 7, 9, and $100 \mathrm{MC}$ iterations for each of the four steps respectively. This set is consistent with Sekovski et al. (2015), who examined coastal vulnerability to flooding at a similar geographical scale.

Four MC runs were conducted in the coarse calibration, and the widest range of the parameters, 0 to 100 , were evaluated with an increment of 25 at a time. The goodness of fit in models was assessed by 13 metrics, the majority of which were least-square regression scores between simulated urban components (e.g., increased urban pixels and clusters) and real counterparts. SLEUTH scholars, however, largely debated the selection of the optimal metric which could determine model performance. Most disputes centered on whether a combination of several indicators outperform a single metric. Dietzel and Clarke (2007) developed a composite metric, known as Optimal SLEUTH Metric (OSM). The OSM is the product of the compare, population, edges, clusters, slope, $x$ mean, and $y$ mean metrics. The authors evaluated different combinations of the 13 metrics and found that OSM contributes to more accurate and superior predictions than single-metric approaches. Recent studies have furthermore suggested OSM's robustness (Jantz et al., 2010; Sakieh et al., 2015). Hence, it was applied in this work to narrow parameter ranges after each stage. Specifically, seven MC iterations with narrower parameter ranges were employed in the fine stage. Further refined ranges of the parameters with nine $\mathrm{MC}$ iterations were next tested during the final calibration.
This whole process took around 1-month process time and was conducted using the standard 3.0 SLEUTH model executed in the Cygwin UNIX Windows compiler. This threestage process generated five candidate parameters; however, this set may be biased due to the self-modification nature of SLEUTH. Therefore, a deriving calibration with the candidate set was performed with $100 \mathrm{MC}$ iterations.

\subsubsection{Model prediction}

Three approaches have been widely applied in the literature. The first is to adjust one or more of the five parameters (Leao et al., 2004; Rafiee et al., 2009). The second is to modify the growth-resistance levels in excluded layers (Jantz et al., 2010) or apply distinct excluded layers (Akın et al., 2014). The last one, less frequently used than the first two methods, is to alter self-modification parameters which control overall growth rates (Yang and Lo, 2003). This research used a combination of the first two approaches, and the results were overlaid with SLR-induced flooding maps. The urban growth was predicted up to 2080, and the exposure to flooding under different growth patterns and policies were analyzed in 2030 and 2080.

As in widespread use in similar studies, this work first simulated three growth patterns: historical growth (HUG), urban sprawl (USG), and compact development (CUG). The HUG assumed that prospective urban extent expanded at an existing growth rate, and five parameters remained unchanged over the forecasting period. The USG resulted in more scattered urban communities. In the model, the dispersion, breed, 


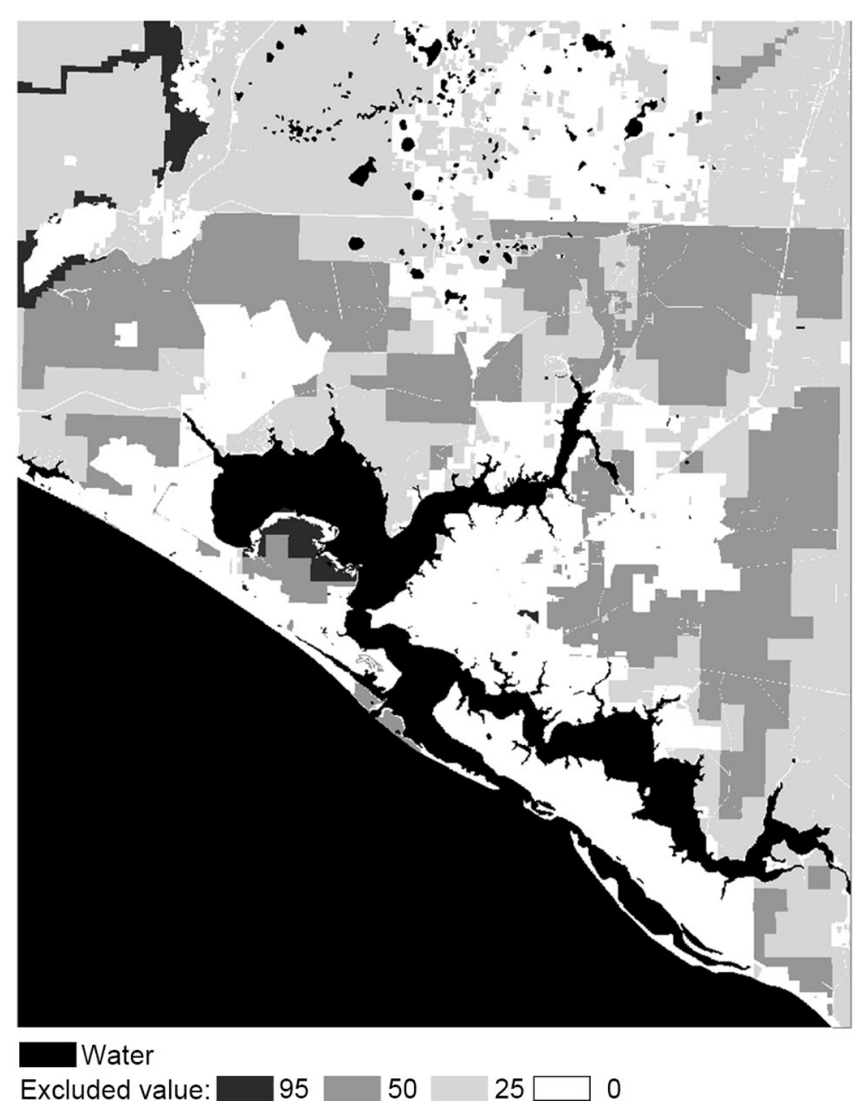

Figure 6. The E2 excluded layer (based on current zoning plans). For the excluded layer, higher value represents higher resistance to urban growth. The value ranges from 0 to 100 .

and road gravity factors controlled sprawling growth (Table 2), so increasing these parameters produced more dispersed developments. In contrast, the CUG is characterized by the enlargement of current settlements. Compact development is apparent in Bay Country and many other populated coastal regions. In SLEUTH, compact development was positively associated with the spread parameter (Table 2). In addition, decreasing road gravity inhibited new growth along corridors and thus contributed to compact urban forms (Table 2).

These growth patterns were next simulated under three policy scenarios: flood mitigation (E1, based on the whole region), conservational/agricultural land protection (E2), and modified flood mitigation (E3, based on the AMLEG). E1 restrained growth in low-lying areas and served as an adaptation strategy to SLR. Alternatively, E2 reflected how future city expansion may be impacted by zoning that represents a strong predictor of urban growth in Florida (Onsted and Chowdhury, 2014). E3 is a modified scenario of the flood mitigation due to heterogeneous urban growth. Finally, these predictions were coupled with SLR-induced flooding.

\subsection{SLR-induced flooding maps}

The detailed methodology for generating SLR-induced flooding was developed by Hsu (2014). In his hurricane model, the effects of rise in sea level and sea surface temperature (SST) were considered in two stages. First, the increase in SST decreased central hurricane pressure over the sea surface (Knutson and Tuleya, 2004). Changed central pressure and other parameters were next used to calculate projected surge heights using the surge response function (SRF) developed by Irish et al. (2009). Based on this information, a hypothetical hurricane was projected to make landfall at a place where it caused the most damages to coastal areas and resulted in a 500-year flood. Second, the projected surge height was adjusted by local SLR (Udoh, 2012). Two extreme SLR scenarios were considered, as shown in Table 5. A1F1 corresponded to the highest level of global greenhouse gas emissions (IPCC, 2007). Next, different surge heights were calculated in numerous SRF stations which were defined along the coastline of Bay County. SRF zones associated with each station were delineated, and each zone had a height value. Finally, flooding areas were identified by comparing surge heights and local elevation data. All the required data sets regarding projected SLR and SST were collected from the fourth assessment report published by the IPCC (2007) (Table 5).

\section{Results and discussions}

\subsection{Model calibration}

The multi-stage calibration process generated the following parameters: 71 (dispersion), 92 (breed), 70 (spread), 3 (slope), and 35 (road gravity). High values of the first three parameters suggest that the past several decades have witnessed apparent urban sprawl and growth surrounding established settlements. As indicated in Fig. 2, the previous urbanization primarily occurred in the vacant areas immediate to central Panama City and southwest shorelines. Such an outward expansion of cities is demonstrated by the breed parameter - the most influential factor affecting urban growth. Additionally, two newly urbanized clusters in the north have appeared and been expanding since 1995 (Fig. 2). Such a spatial structure is largely captured by the dispersion and breed factors: their values are the second (71) and third (70) highest respectively. By contrast, the low value of the slope parameter is understandable since Bay Country has few mountainous areas, and therefore elevation is not a limiting factor. This finding suggests that the weight of elevation can be further reduced in plain regions, pointing out a direction for customizing the data structure of SLEUTH. The road gravity's coefficient is much lower than those of the dispersion, breed, and spread parameters, indicating a limited impact of road systems upon land use allocation. This effect is intuitively 


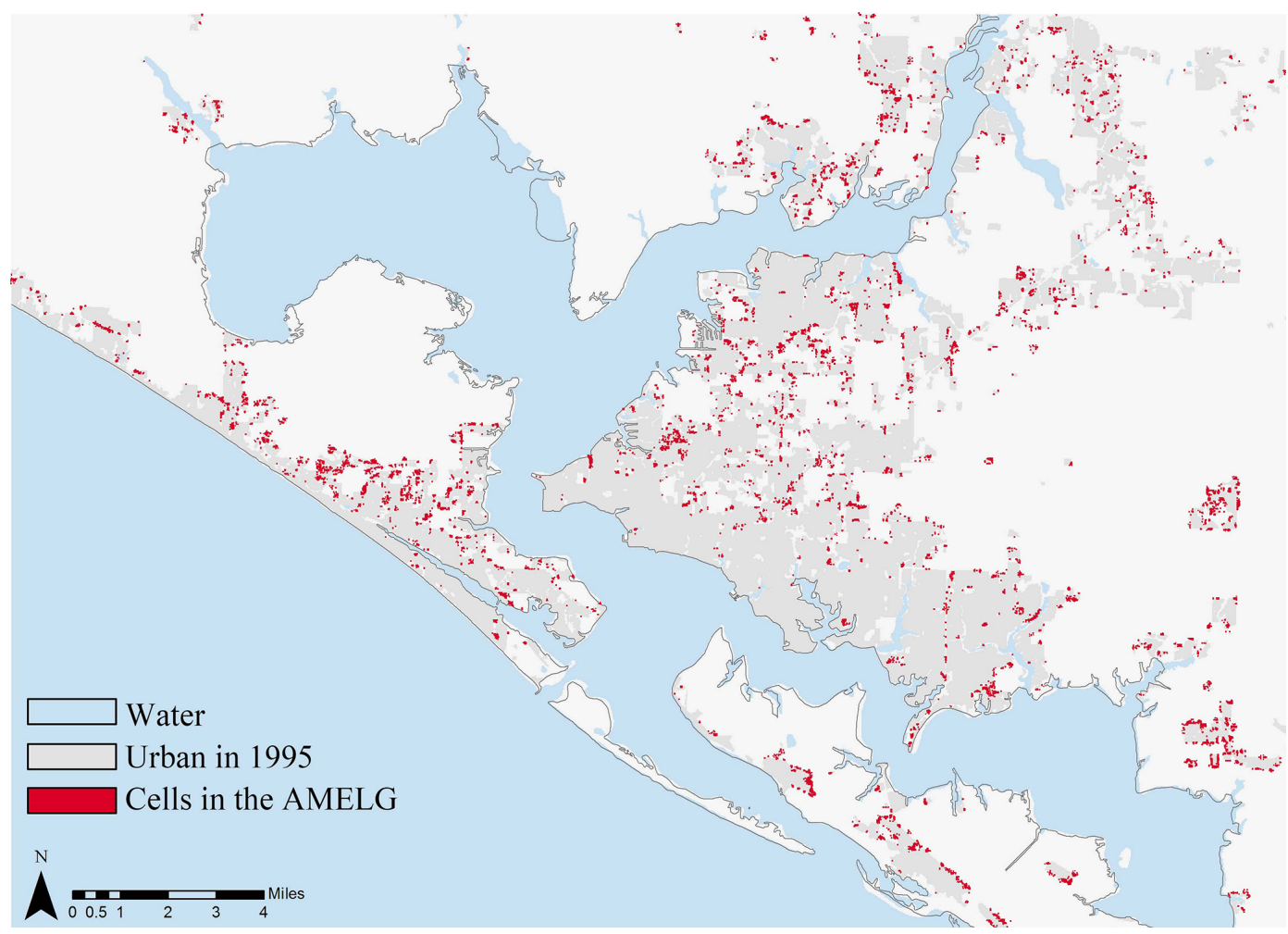

Figure 7. The areas more likely to experience growth (AMLEG) in the coastal region from 1995 to 2013 . The cells with $50 \%$ or more urbanization probability were considered as the AMLEG.

Table 5. Sea surface temperature (SST) changes and sea level rise (SLR) in 2 future years in Panama City, FL.

\begin{tabular}{lrrl}
\hline Climate scenario & $\begin{array}{r}\text { Rise in SST } \\
\left({ }^{\circ}\right)\end{array}$ & $\begin{array}{r}\text { SLR } \\
(\mathrm{m})\end{array}$ & Data sources \\
\hline Present-day & 0 & 0 & \\
A1FI (high) in 2030 & 1.23 & 0.20 & The SST and SLR estimates published by the IPCC. \\
A1FI (high) in 2080 & 5.02 & 0.90 & \\
\hline
\end{tabular}

reasonable in that transportation networks in the study area have remained stable since the 1980s.

\subsection{Model prediction}

It is suggested that a sensitivity analysis should be conducted before predictions to identify the most significant parameter (Sekovski et al., 2015). This assessment was carried out by subsequently setting each parameter as 80 and keeping the others as the lowest value of one and running predictions up to 2030. The results indicate that the spread parameter has the greatest impact on future urban expansion, leading to a $13.99 \%$ increase in urban areas up to 2030.

Different sets of parameters can characterize urban sprawl and compact development. Specifically, urban sprawl is referred to as scattered formed developments along major transportation networks. Conversely, compact developments are in proximity to existing urban areas. Therefore, this work applied the following criteria to develop two alternative scenarios of future urban growth-urban sprawl and CUG.

1. The dispersion, breed, and road gravity's coefficients were increased and decreased by 25 in USG and CUG respectively.

2. The spread's coefficient was raised and lowered by 10 in USG and CUG respectively. Since this parameter was much more influential in urban growth than the others, 10 was selected as an adjusting value in two scenarios.

3. As its impact was quite marginal, the slope parameter remained unchanged across all scenarios. Table 6 summarizes different sets of parameters for three scenarios.

We applied different parameter combinations into the SLEUTH model and generated various maps which showed the probability of each cell being urbanized. These maps 
Table 6. Growth parameters for three scenarios.

\begin{tabular}{lrrrrr}
\hline Scenarios & Dispersion & Breed & Spread & Slope & $\begin{array}{r}\text { Road } \\
\text { gravity }\end{array}$ \\
\hline Historical growth (HUG) & 71 & 92 & 70 & 3 & 35 \\
Urban sprawl (USG) & 96 & 100 & 60 & 3 & 60 \\
Compact development (CUG) & 46 & 67 & 80 & 3 & 10 \\
\hline
\end{tabular}

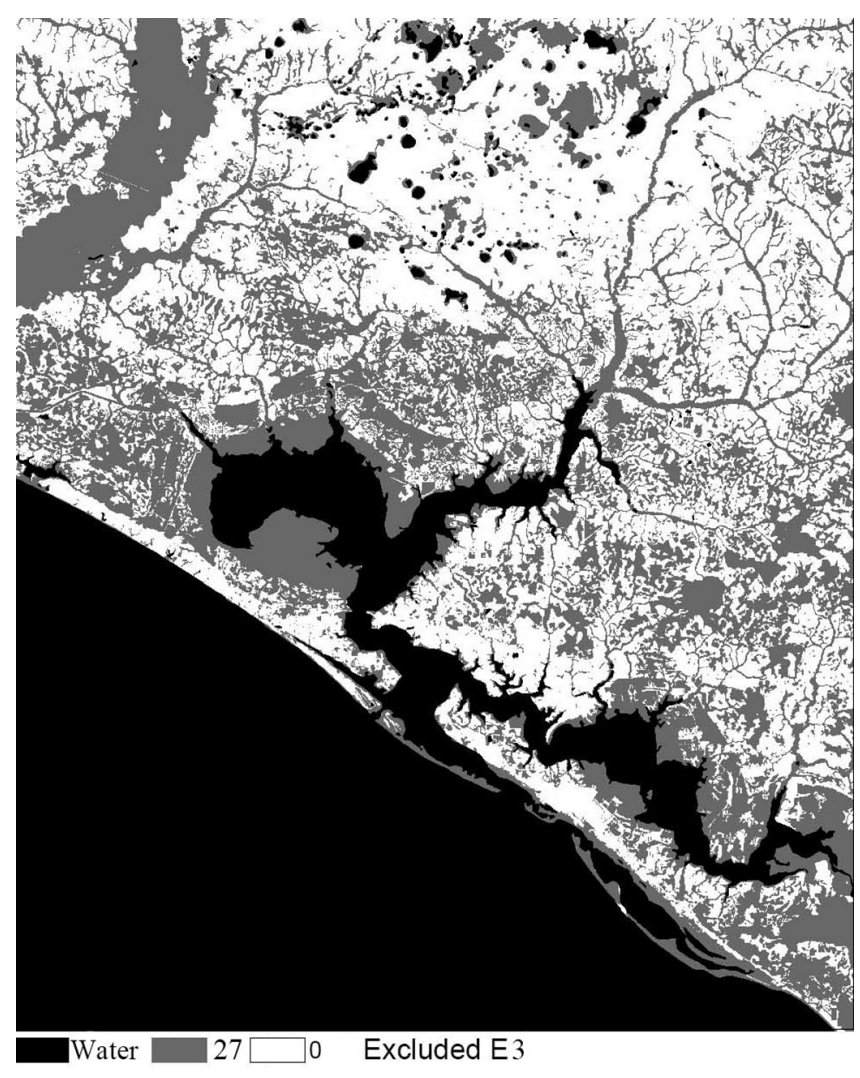

Figure 8. E3 excluded layer (based on the AMLEG technique). The excluded values range from 0 to 100 . A higher value represents larger resistance to urban growth.

were then converted to urban/non-urban results by a cutoff probability value. Here, a justified approach to identify the reasonable cutoff value is to assess the histogram frequency of probabilities (Dezhkam et al., 2013; Rafiee et al., 2009; Wu et al., 2008). After evaluating the projected maps in 2080, we found that there was a steep increase of urbanized cells around the probability of $90 \%$. The cutoff value of 85 was selected to determine whether a cell was converted into urban accordingly.

Figure 9 summarizes the growth statistics with different policies under three urban development scenarios. It shows that, without land use regulations, city areas grow substantially under all scenarios (Fig. 9a). For instance, urban region expands up to $826 \mathrm{~km}^{2}$ in 2080 under the historical growth.
Similar patterns can be seen in alternative growth scenarios as well, as shown in Fig. 9a. Under stricter land use restrictions, the simulations with the E1 excluded layer generate the smallest increase in urban extent from 2013 to 2080 (Fig. 9b). In addition, their growth curves that gradually level off from 2013 indicate a steadily falling growth rate. Under compact growth, which shows the highest rise in urban areas among three scenarios, the city region expands by $15 \%$ within 7 decades (Fig. 9b). This is intuitively reasonable because the flooding map exerts a heavy constraint on undeveloped lands, and therefore new developments largely appear near existing cities and towns. Nonetheless, the predictions with the E3 excluded layer produce approximately the same amount of new growth as those with the E1 layer (Fig. 9d). Similarly, urban growth with the E2 layer (conservational/agricultural land protection) has a similar pattern as the simulations with no regulations. Figure $9 \mathrm{c}$ shows that the growth rate in compact development reaches the peak (19\%) at 2044 and then gradually levels off. However, land use zoning does have an impact on the number of new urban areas. The simulated urban area in 2080 with the historical growth pattern is $709 \mathrm{~km}^{2}$ (Fig. 9c), only $85 \%$ of that under no restrictions (Fig. 9a). In sum, spreading development from existing coastal areas is the leading force behind land use changes. Second, the changes are also driven by the dispersion, breed, and road parameters but less associated with the slope factor.

Figure 10 shows predicted urban growth up to 2080 under different excluded layers. These illustrations further depict urban expansion trends indicated by the growth curves in Fig. 9. In other words, historical growth and urban sprawl share similar developmental patterns where the majority of projected urban cells appear under flexible land use regulations. Moreover, a considerable portion of urban expansion would fall into flooding zones if no land use policy is implemented.

\subsection{The exposure of urban growth to flooding risk}

Figure 11 shows 500 -year flooding maps that would be exacerbated by SLR in 2030 and 2080. Large areas immediate to the west, north, and east bays would be flooded, and the regions adjacent to the west and north bays would be even more susceptible in 2080. As shown in Table 7, the total inundated area in 2080 would be more than 10 times that in 2030. Additionally, the total number of lands with a flooding depth over $3 \mathrm{~m}$ would rise considerably from 2030 to 2080 . 

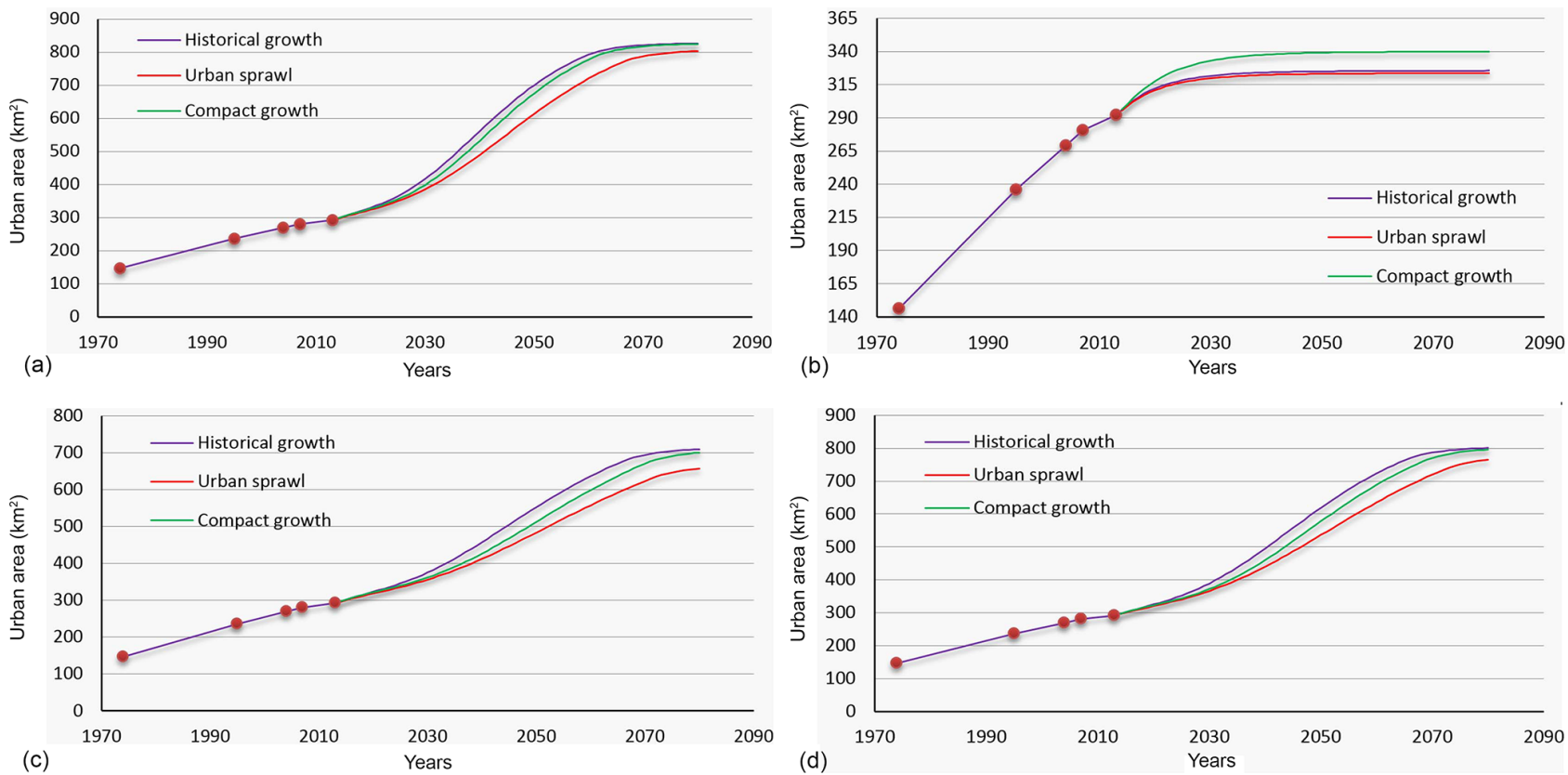

Figure 9. Simulations of urban changes to the year 2080 of three urban growth patterns under four excluded layers. (a) E0: water bodies. (b) E1: flood mitigation strategy (based on the whole region). (c) E2: conservational/agricultural land protection. (d) E3: flood mitigation strategy (based on the AMLEG).

Future urban simulations were overlaid with flooding maps to show how different developmental patterns guided by distinct policies are vulnerable to SLR-induced flooding (Tables 8-9). The results unveil that, if urban growth progresses compactly, total inundated area in 2030 would be the largest among three growth scenarios (Table 8). For land use policies, urban growth under regulations leads to less floodprone developments. By contrast, if no regulations are implemented, the total inundated area of projected urbanized cells in 2080 is $111.243 \mathrm{~km}^{2}$ on average, more than 25 times the area in the flood mitigation strategy based on the whole region (Table 9). Therefore, both growth patterns and land use policies have substantial impact on the susceptibility of coastal cities to flooding hazards.

Figure 12 shows how three urban growth scenarios are exposed differentially to SLR-induced flooding at a larger geographical scale. It suggests that urban growth is extremely limited if we implement the excluded layer that represents the flood mitigation based on the whole region. Conversely, if water bodies are used as an excluded layer, urban areas expand considerably in coastlines and hinterlands. Noticeably, urban expansion with the E3 excluded layer also generates a vulnerable landscape to flooding. This phenomenon reflects heterogeneous developments over the study region. Coastal areas would probably continue to be urbanized even if they are threatened by flooding and storm surge. Such a pattern may be partly because the high value of properties along shorelines diminishes SLR impacts. Protective structures and
Table 7. Flooded areas under 0.2 and $0.9 \mathrm{~m}$ sea level rise scenarios.

\begin{tabular}{lrr}
\hline Flooding depth $(\mathrm{m})$ & \multicolumn{2}{c}{ Area $\left(\mathrm{km}^{2}\right)$} \\
\cline { 2 - 3 } & $\begin{array}{rrr}0.2 \mathrm{~m} \text { sea } \\
\text { level rise } \\
(2030)\end{array}$ & $\begin{array}{r}0.9 \mathrm{~m} \mathrm{sea} \\
\text { level rise }\end{array}$ \\
& 4.6 & 58.8 \\
\hline $0-0.5$ & 4.3 & 52.5 \\
$0.5-1$ & 7.0 & 100.3 \\
$1-2$ & 7.0 & 77.7 \\
$2-3$ & 8.2 & 176.1 \\
$>3$ & 31.1 & 465.4 \\
\hline Total & &
\end{tabular}

flood-insurance programs even attract new developments in flood-prone areas.

\subsection{Discussion}

\subsubsection{Modeling and uncertainties}

According to Box and Draper (1987), "Essentially, all models are wrong, but some are useful" (p. 424). Simulations are different levels of the approximations of real-world phenomena. This norm also applies to this work. The primary contribution of this paper is to seek methodological incorporation between urban growth models and SLR-induced flooding, although it attempts to tie land use predictions with coastal planning practice. However, this research suffers from a few 

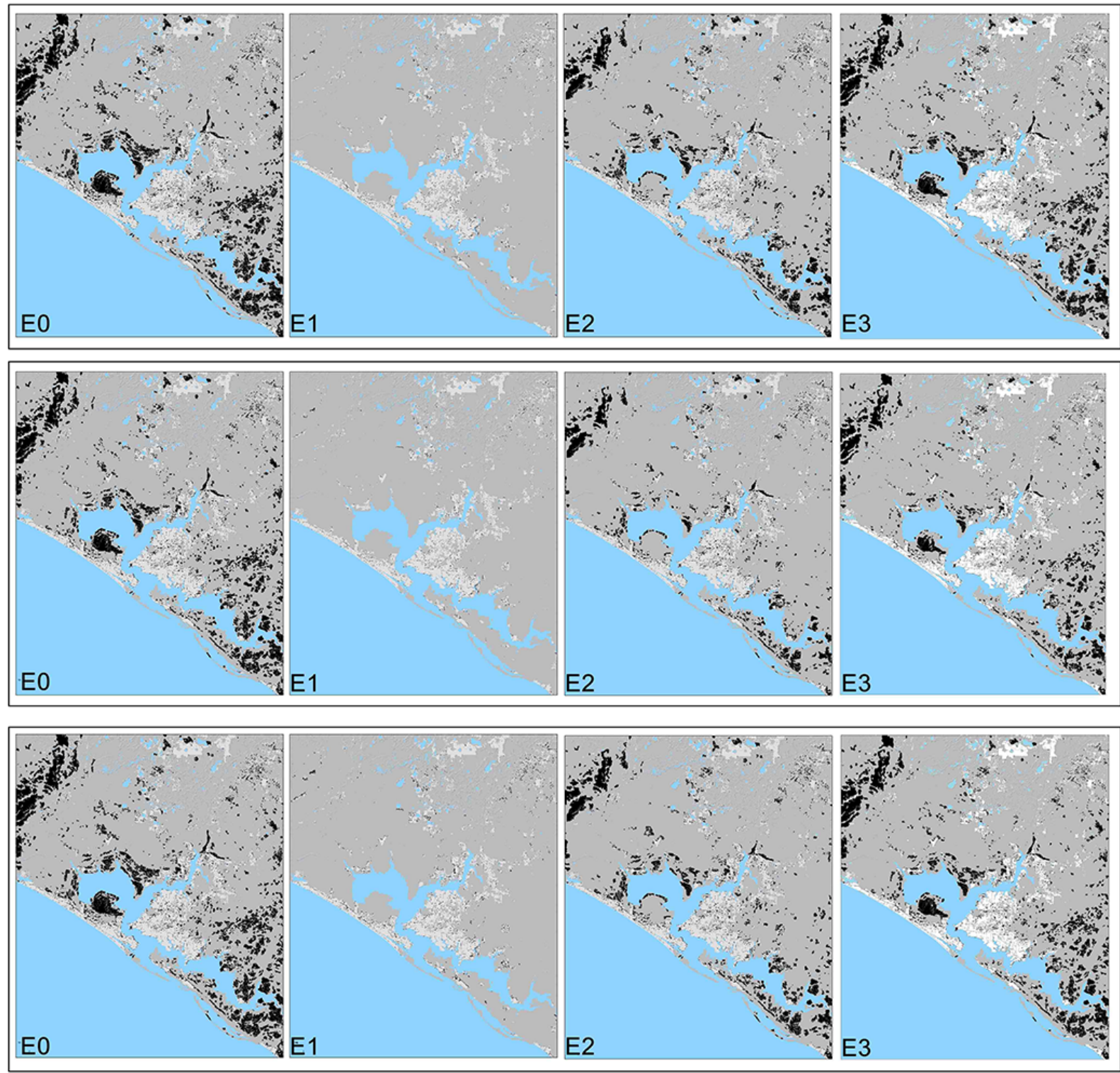

\begin{tabular}{|c|c|c|c|}
\hline \multirow[t]{4}{*}{ Layout: } & Historical growth & Legend: & \\
\hline & & \begin{tabular}{|l} 
\\
\end{tabular} 2013 urban & Simulated growth from 2013 to \\
\hline & Utodil spiavi & Hillshade & Miles \\
\hline & Compact growth & Water & \\
\hline
\end{tabular}

Figure 10. Comparison of modeled urban extent in 2080 with different excluded layers. E0: water bodies. E1: flood mitigation (based on the whole region). E2: conservational/agricultural land protection. E3: flood mitigation (based on the AMLEG).

limitations associated with the case study region, assumptions, and uncertainties.

First, Bay County is a typical land-sea interface confronted with heightened pressure from SLR, and the results are analogous to those in other similar coastal zones. However, we inadequately evaluate the effect of elevation on urban exposure to flooding. Thus, our findings may have limited comparability with hilly areas.
Second, the SLEUTH model in its current form excludes several critical variables contributing to urban dynamics. It may insufficiently capture various factors affecting urbanization (Herold et al., 2003). The demand for urban growth comes from population and economic increase. The Bureau of Economic and Business Research (2016) forecasts that the total population of Bay County will increase by almost $40 \%$ by 2030 . Such a rise demands additional urbanization capaci- 

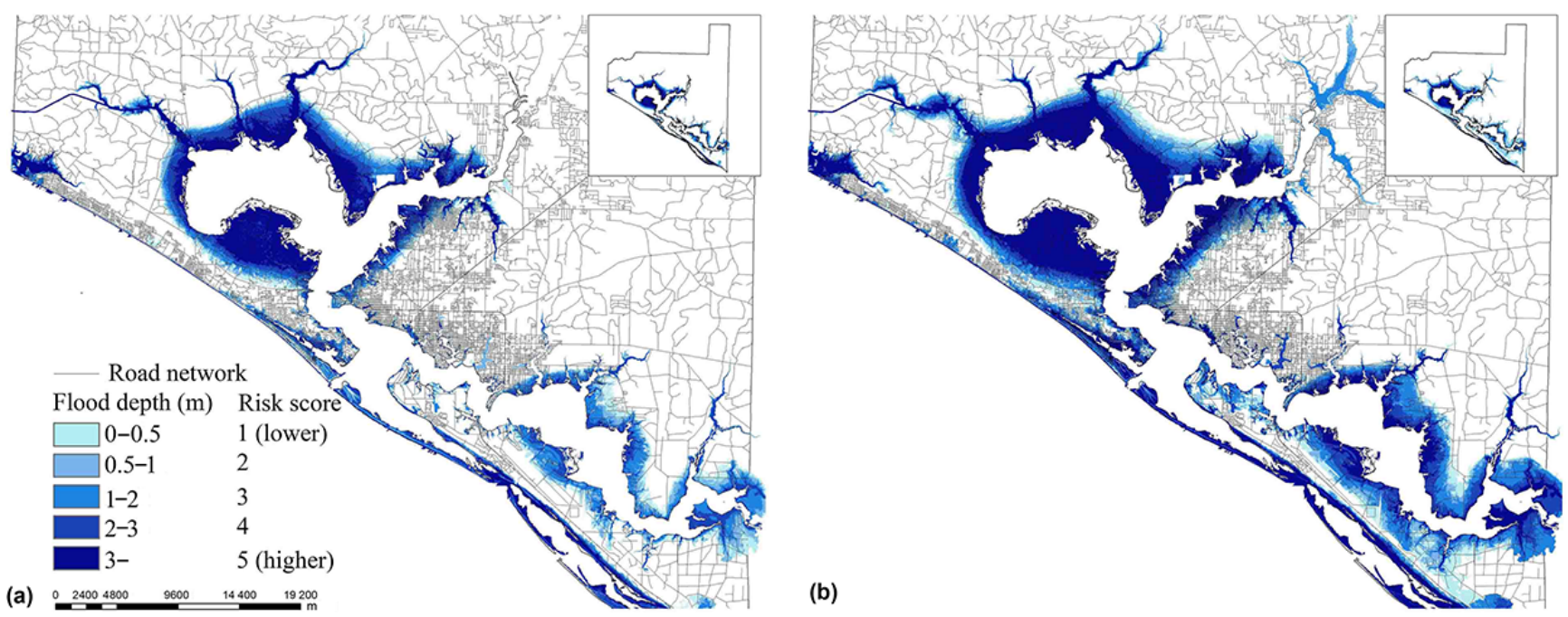

Figure 11. The 500-year flood-risk zones of $0.2 \mathrm{~m}$ sea level rise (SLR) (a) and 0.9 m SLR (b).

Table 8. The results of overlaying urban growth predictions with the 500-year flooding map in 2030.

\begin{tabular}{|c|c|c|c|c|}
\hline \multirow[t]{2}{*}{ Excluded layers } & \multirow[t]{2}{*}{ Flooded areas } & \multicolumn{3}{|c|}{ Urban growth scenarios } \\
\hline & & HUG & USG & CUG \\
\hline \multirow[t]{2}{*}{ E0: no regulations } & Total flooded area $\left(\mathrm{m}^{2}\right)$ & 59112900 & 57466800 & 59185800 \\
\hline & New urban areas that would be flooded $\left(\mathrm{m}^{2}\right)$ & 7254000 & 5607900 & 7326900 \\
\hline \multirow[t]{2}{*}{ E1: flood-risk mitigation (based on the whole region) } & Total flooded area $\left(\mathrm{m}^{2}\right)$ & 53223300 & 52974900 & 54468900 \\
\hline & New urban areas that would be flooded $\left(\mathrm{m}^{2}\right)$ & 1364400 & 1116000 & 2610000 \\
\hline \multirow[t]{2}{*}{ E2: conservational/agricultural land protection } & Total flooded area $\left(\mathrm{m}^{2}\right)$ & 58479300 & 56867400 & 58603500 \\
\hline & New urban areas that would be flooded $\left(\mathrm{m}^{2}\right)$ & 6620400 & 5008500 & 6744600 \\
\hline \multirow[t]{2}{*}{ E3: flood-risk mitigation (based on the AMLEG) } & Total flooded area $\left(\mathrm{m}^{2}\right)$ & 57974400 & 56486700 & 58048200 \\
\hline & New urban areas that would be flooded $\left(\mathrm{m}^{2}\right)$ & 6115500 & 4627800 & 6189300 \\
\hline
\end{tabular}

Note: HUG is historical urban growth, USG is urban sprawl growth, and CUG is compact development.

ties. Therefore, future applications should consider socioeconomic factors behind urbanization. Population growth, however, is linked with migration, overall economic conditions, and other factors, which are complicated and hard to predict. Additionally, urbanization in coastal regions is driven by economic activities, the majority of which are related to tourism and real estate. Nevertheless, CA models rarely integrate these factors.

Third, this paper is based on several assumptions to forecast urban landscape evolution. It determines the excluded values of the E2 scenario according to future land use plans and suggestions from other studies (e.g., Akın et al., 2014). Although the lack of zoning information forced us to make this assumption, the predictions under the E2 may become problematic. Besides, the extrapolation of future urban growth beyond the calibration range can be questionable and generate uncertain results (Goldstein et al., 2004). Modelers ought to make a trade-off between land use predictions and the projections of climate-change-related hazards. Climate change is slow going, but urbanization may be rapid in populated coastal regions. For instance, SLR may become significant only after an adequate period that probably exceeds that of historical urban data. Such coupled analyses should aim at identifying the general impacts of climate change on future urbanization, rather than replicating the past urban patterns. The last assumption relates to adaptation strategies. SLEUTH fails to incorporate seawall, population relocation, and other adaptation strategies to SLR. This limitation can be seen in the given examples of future flooding risks (Fig. 12). Many existing urban areas would fall into flooding polygons in 2030 and 2080. Essentially, the model assumes a "do-nothing" option regarding adaptation strategies; such a limitation is addressed in a following paper.

Eventually, uncertainties come from two aspects. The "best-fit" parameters are nondeterministic and estimated by distinct numbers of MC iterations in different calibration stages. Thus, when comparing this work's numerical results with those of similar research, readers should be aware of the stochastic nature of the model. Second, additional concerns arise when it comes to SLR projections and their impacts on 
Table 9. The results of overlaying urban growth predictions with the 500-year flooding map in 2080.

\begin{tabular}{|c|c|c|c|c|}
\hline \multirow[t]{2}{*}{ Excluded layers } & \multirow[t]{2}{*}{ Flooded areas } & \multicolumn{3}{|c|}{ Urban growth scenarios } \\
\hline & & HUG & USG & CUG \\
\hline \multirow[t]{2}{*}{ E0: no regulations } & Total flooded area $\left(\mathrm{m}^{2}\right)$ & 200035800 & 185077800 & 199561500 \\
\hline & New urban areas that would be flooded $\left(\mathrm{m}^{2}\right)$ & 116387100 & 101429100 & 115912800 \\
\hline \multirow[t]{2}{*}{ E1: flood-risk mitigation (based on the whole region) } & Total flooded area $\left(\mathrm{m}^{2}\right)$ & 87068700 & 86526900 & 89570700 \\
\hline & New urban areas that would be flooded $\left(\mathrm{m}^{2}\right)$ & 3420000 & 2878200 & 5922000 \\
\hline \multirow[t]{2}{*}{ E2: conservational/agricultural land protection } & Total flooded area $\left(\mathrm{m}^{2}\right)$ & 168683400 & 141254100 & 164392200 \\
\hline & New urban areas that would be flooded $\left(\mathrm{m}^{2}\right)$ & 85034700 & 57605400 & 80743500 \\
\hline \multirow[t]{2}{*}{ E3: flood-risk mitigation (based on the AMLEG) } & Total flooded area $\left(\mathrm{m}^{2}\right)$ & 181416600 & 155827800 & 179401500 \\
\hline & New urban areas that would be flooded $\left(\mathrm{m}^{2}\right)$ & 97767900 & 72179100 & 95752800 \\
\hline
\end{tabular}

Note: HUG is historical urban growth, USG is urban sprawl growth, and CUG is compact development.

hurricanes. Researchers have not yet reached an agreement as to SLR estimates; sea level may increase more rapidly than people initially thought. Nicholls and Cazenave (2010) reviewed numerous sources and concluded that globally mean sea level would rise between 0.19 and $1.7 \mathrm{~m}$ by 2100 . Given these uncertainties, therefore, the simulation results should be interpreted with caution.

\subsubsection{Urban growth and coastal hazards}

The calibration results indicate that main driving force for the study area is spread, followed by dispersion and breed. Such findings are in line with similar coastal studies (Sakieh et al., 2015; Sekovski et al., 2015). In other words, urban growth is likely to take place around current settlements in a compact fashion. Existing settlements are featured by excellent accessibility to infrastructure, activity centers, and coastal amenities. Additionally, a multitude of new urban areas cluster around coastlines, which is evident either in the business-asusual or urban sprawl scenarios. Increased human activities and the competition for limited resources, therefore, intensify environmental pressures at land-sea interfaces. Furthermore, the interface faces unprecedented threats from SLR and other intensified coastal hazards. SLEUTH could provide useful information about future urban growth and thus benefit coastal city managers and land use planners.

\subsubsection{Policy implications}

Compact urban forms are advocated because of their environmental friendliness and benefits for energy conservation (Dezhkam et al., 2013; Mahiny and Gholamalifard, 2007). However, this might not be true in flat coastal areas from the perspective of hazard mitigation. As indicated in Tables 8 and 9, the compact growth scenario generates more extension of current flood-prone areas than the scenarios of historical growth and urban sprawl. For instance, if the flood mitigation policy is implemented, new built-up regions that would be flooded in 2030 under the compact growth pattern are over $2.5 \mathrm{~km}^{2}$, almost double the area under historical growth scenario. However, such conclusions are made only based on our case study area where slopes change insignificantly. Thus, the effects of compact urban forms on flooding exposure require further investigation in other coastal regions with different topographical features.

Population and economic growth largely drive urban expansion. Nevertheless, policies behind such growth should also be investigated since these policies (e.g., land use plans and economic strategies) represent developmental blueprints. Thus, it is beneficial to reflect upon how policies contribute to distinct urban growth patterns: urban sprawl and compact growth. Urban sprawl is characterized by unplanned and scattered developments in suburban areas. Uncoordinated growth in the city edge has been suggested to relate to multidimensional factors regarding economic incentives, housing development plans, and transportation policies (De Vos and Witlox, 2013; Lopez and Hynes, 2003; Yue et al., 2016). Economic incentive packages launched by the central government have contributed to urban sprawl in the developing world. For instance, China took an economic reform in the 1970s by opening up land markets and commercializing housing units. This economic stimulus gave rise to many sprawling megacities such as Beijing, Shanghai, and Chengdu. In Europe and North America, though, microeconomic theories may majorly explain urban sprawl. For example, households begin to relocate to the suburbs when the land prices in city centers become prohibitively high. Their relocation decisions are further strengthened by housing and land development policies. Developers promote low-density communities in the city periphery. Local governments help build large retail centers to accommodate the increased demands. Motorization policies and low fuel costs result in automobile-oriented cities. Even public transit policies aggravate outward city growth by charging long-distance commuters less than the riders for short distances (De Vos and Witlox, 2013).

As urban sprawl increasingly threatens public health, social equity, and the built environments, people start to develop different urban containment policies. There are primarily two forms of containment policies that were adopted in the USA. The state law in Oregon and Washington re- 

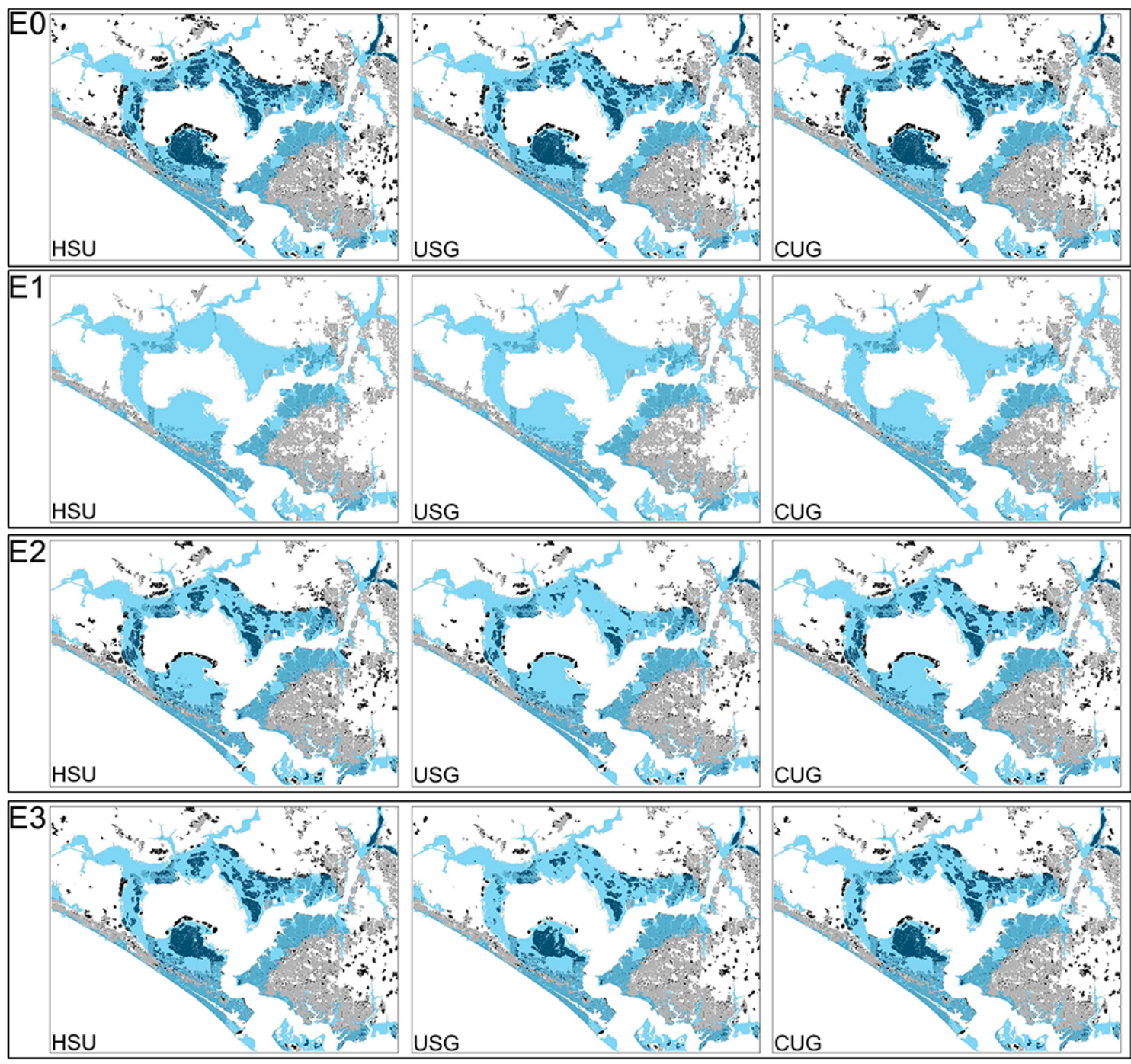

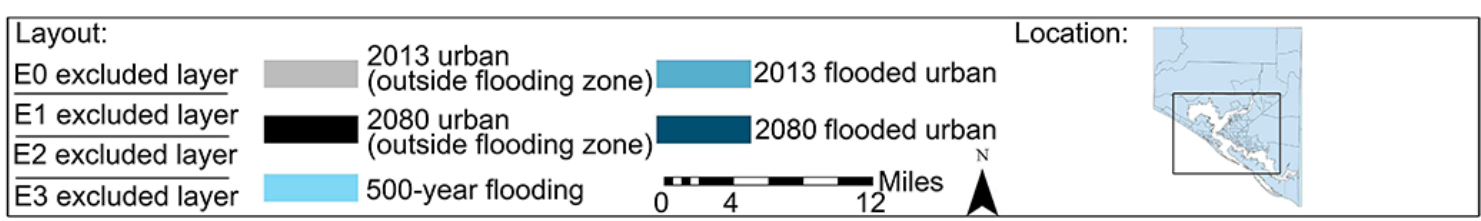

Figure 12. Flooded urban extent in 2080. E0: water bodies. E1: flood mitigation strategy (based on the whole region). E2: conservational/agricultural land protection. E3: flood mitigation strategy (based on the AMLEG). HSU: historical growth. USG: urban sprawl. CUG: compact development.

quires that local land use plans should clearly define an urban growth boundary. In other states such as Florida and Maryland, governments develop urban service limits, public facilities ordinances, and other policies to promote compact urban forms (Aytur et al., 2008). However, the effects of urban containment policies have been hotly debated. For example, not all urban growth boundaries significantly affect housing markets and the rates of urbanization (Dempsey and Plantinga, 2013). Thus, De Vos and Witlox (2013) suggest the integration of spatial planning policies, mobility policies, and road pricing. Spatial planning can strictly limit new developments outside urban areas. Transit-oriented development benefits nurturing high-density and mixed land use neighborhoods. Lastly, road pricing increases long-distance travel costs, thereby curtailing urban sprawl.

The modeling approaches and results offered by this work could aid in the development of an integral land use enforcement system. Building a comprehensive land use policy for the urban growth landscape is a recommended option in coastal communities, which is currently lacking in existing 
principal planning practices for future SLR in the USA (Fu et al., 2016). An integrative policy framework can coordinate the increased demand for urbanization and the goal for hazard mitigation. In other words, planners ought to incorporate the zoning of existing coastal areas into the adaptation strategies to SLR and develop rural land use regulations that attract new development inland. While prohibiting developments within flooding zones partly constrains urban growth and may be unrealistic, only relying on zoning could lead to massive areas subject to flooding. A compromise of these two alternatives, accordingly, could be developed to both ensure adequate urbanization and steer new developments away from low-lying areas. Finally, planners should also consider seawall, planned retreat, and other adaptation strategies as key components of the proposed framework to protect existing urban areas from being inundated. Furthermore, in the long term, policy makers should formulate adaptation plans that address other SLR aspects such as groundwater pollution and saltwater intrusion beneath protective structures.

\section{Conclusions}

Environmental and resource pressures are intensified given ongoing coastal urbanization. Besides, the urbanization process amplifies the exposure of coastal communities to flooding hazards. Unfortunately, we are uncertain about the degree to which SLR may contribute to the increased intensity of storminess. The possibility of more exacerbated consequences, however, cannot be neglected from a precautionary perspective. Therefore, it is crucial to building an effective coastal management plan to balance land use, competing interests, and hazard mitigation.

This work contributes to the literature by integrating urban growth dynamics, land use policies, and SLR-induced flooding. We successfully calibrated the SLEUTH model for Bay County, Florida (USA), based on historical data from the year 1974 to 2013. By applying the best-fit coefficients, we developed three urban growth scenarios and assessed the exposure of future urban extent to SLR-induced flooding under different land use policies. These scenarios reflected various growth strategies that are widely applied in urban planning. Our results indicate that the parameters associated with compact development largely drive urban growth in Bay County and similar coastal communities. The results show that substantial urban growth would be prone to coastal flooding if no land use policy is implemented.

SLEUTH is particularly useful in modeling complex spatial dynamics. Moreover, the computational capacity of SLEUTH is greatly enhanced due to the rapid advancement of computer technologies. Being able to outputting GIF maps and statistics for each predictive year, SLEUTH can be easily linked with a raster-based GIS environment (Rafiee et al., 2009). Therefore, modelers can readily import the results of different scenarios into a GIS platform for presentation pur- poses. Such a coupled model serves as a decision support tool and helps land use planners, and hazard mitigation teams evaluate the outcomes of different policies. Additionally, the visualization results can be used to raise general awareness about the vulnerability of coastal communities to SLR.

Admittedly, models are just the simplifications of reality, and urban growth is an intricate process that involves population increase, economic activities, and many other factors. Since the level of SLR impact on flooding is quite unclear, and growth predictions could be probably biased, the model cannot generate exact results regarding urban growth and flooding extent. However, we believe that the "whatif" estimations are useful in helping decision makers understand how policies mould distinct developmental patterns. Therefore, probabilistic models and scenario-based planning should be advocated to evaluate planning alternatives and their consequences (Xiang and Clarke, 2003) as well as to offer reliable estimates of flooding damages.

Data availability. The original model code can be accessed at the following link: http://www.ncgia.ucsb.edu/projects/gig/Dnload/ download.htm (Project Gigalopolis, 2016). For the access to the comprehensive inputs and outputs of the models, please feel free to contact the authors (zpeng@ufl.edu or songjiescu@ufl.edu).

Competing interests. The authors declare that they have no conflict of interest.

Acknowledgements. The authors highly appreciate Keith C. Clarke for his help throughout the modeling process. The authors greatly appreciate Chih-Hung Hsu for developing flooding maps. The authors also thank the US Census Bureau, the Florida Geographic Data Library, the Bay County Online, and the Bureau of Economic and Business Research for offering access to their data. This paper was undertaken with the support from the Florida Sea Grant, grant no. R/GOM-RP-2, "A Parameterized Climate Change Projection Model for Hurricane Flooding, Wave Action, Economic Damages, and Population Dynamics". This paper was also funded by the Florida Sea Grant Project entitled "A Spatial-Temporal Econometric Model to Estimate Costs and Benefits of Sea-Level Rise Adaptation Strategies". This work received financial support from the University of Florida Graduate School Dissertation Award, and the publication of this article was funded in part by the University of Florida Open Access Publishing Fund. Last not but the least, the authors' gratitude is given to the editor, Nadia Pinardi, and to two anonymous reviewers who offered constructive comments to help to improve this paper.

Edited by: N. Pinardi

Reviewed by: two anonymous referees 


\section{References}

Akın, A., Clarke, K. C., and Berberoglu, S.: The impact of historical exclusion on the calibration of the SLEUTH urban growth model, Int. J. Appl. Earth Obs., 27, 156-168, doi:10.1016/j.jag.2013.10.002, 2014.

Apel, H., Martínez Trepat, O., Hung, N. N., Chinh, D. T., Merz, B., and Dung, N. V.: Combined fluvial and pluvial urban flood hazard analysis: concept development and application to Can Tho city, Mekong Delta, Vietnam, Nat. Hazards Earth Syst. Sci., 16, 941-961, doi:10.5194/nhess-16-941-2016, 2016.

Aytur, S. A., Rodriguez, D. A., Evenson, K. R., and Catellier, D. J.: Urban Containment Policies and Physical Activity: A TimeSeries Analysis of Metropolitan Areas, 1990-2002, Am. J. Prev. Med., 34, 320-332, doi:10.1016/j.amepre.2008.01.018, 2008.

Bay County Online: Future land use and zoning, available at: http: //www.baycountyfl.gov/gis.php, last access: 26 December 2016.

Berberoğlu, S., Akın, A., and Clarke, K. C.: Cellular automata modeling approaches to forecast urban growth for adana, Turkey: A comparative approach, Landscape Urban Plan., 153, 11-27, doi:10.1016/j.landurbplan.2016.04.017, 2016.

Box, G. E. and Draper, N. R.: Empirical model-building and response surfaces, Vol. 424, Wiley, New York, 1987.

Bureau of Economic and Business Research: Total population in Bay County, University of Florida, available at: https://www. bebr.ufl.edu/population, last access: 9 April 2016.

Chakraborty, A., Wilson, B., and Kashem, S. B.: The pitfalls of regional delineations in land use modeling: Implications for Mumbai region and its planners, Cities, 45, 91-103, doi:10.1016/j.cities.2015.03.008, 2015.

Clarke, K. C., Hoppen, S., and Gaydos, L.: A Self-Modifying Cellular Automaton Model of Historical Urbanization in the San Francisco Bay Area, Environ. Plann. B, 24, 247-261, doi:10.1068/b240247, 1997.

Dempsey, J. A. and Plantinga, A. J.: How well do urban growth boundaries contain development? Results for Oregon using a difference-in-difference estimator, Reg. Sci. Urban Econ., 43, 996-1007, doi:10.1016/j.regsciurbeco.2013.10.002, 2013.

De Vos, J. and Witlox, F.: Transportation policy as spatial planning tool; reducing urban sprawl by increasing travel costs and clustering infrastructure and public transportation, J. Transp. Geogr., 33, 117-125, doi:10.1016/j.jtrangeo.2013.09.014, 2013.

Dezhkam, S., Amiri, B. J., Darvishsefat, A. A., and Sakieh, Y.: Simulating the urban growth dimensions and scenario prediction through sleuth model: a case study of Rasht County, Guilan, Iran, GeoJournal, 79, 591-604, doi:10.1007/s 10708-013-9515-9, 2013.

Dietzel, C. and Clarke, K. C.: Toward optimal calibration of the SLEUTH land use change model, Transactions in GIS, 11, 2945, doi:10.1111/j.1467-9671.2007.01031.x, 2007.

Ebert, K., Ekstedt, K., and Jarsjö, J.: GIS analysis of effects of future Baltic sea level rise on the island of Gotland, Sweden, Nat. Hazards Earth Syst. Sci., 16, 1571-1582, doi:10.5194/nhess-161571-2016, 2016.

Felsenstein, D. and Lichter, M.: Introduction to the special issue on simulating the dynamics of land use change in coastal areas, Ocean Coast. Manage., 101, 61-62, doi:10.1016/j.ocecoaman.2014.09.014, 2014.
Florida Department of Transportation: Florida land use cover and forms classification system: handbook. Surveying and mapping office, Thematic mapping section, Tallahassee, FL, 1999.

Florida Geographic Data Library: available at: http://www.fgdl.org/ metadataexplorer/explorer.jsp, last access: 1 March 2016.

Fu, X., Gomaa, M., Deng, Y., and Peng, Z.-R.: Adaptation planning for sea level rise: a study of US coastal cities, J. Environ. Plann. Man., 60(2), 249-265, doi:10.1080/09640568.2016.1151771, 2016.

Garcia, E. S. and Loáiciga, H. A.: Sea-level rise and flooding in coastal riverine flood plains, Hydrolog. Sci. J., 59, 204-220, doi:10.1080/02626667.2013.798660, 2014.

Goldstein, N. C., Candau, J. T., and Clarke, K. C.: Approaches to simulating the "March of Bricks and Mortar", Computers, Environment and Urban Systems, 28, 125-147, doi:10.1016/S01989715(02)00046-7, 2004.

Hansen, H. S.: Modelling the future coastal zone urban development as implied by the IPCC SRES and assessing the impact from sea level rise, Landscape Urban Plan., 98, 141-149, doi:10.1016/j.landurbplan.2010.08.018, 2010.

Herold, M., Goldstein, N. C., and Clarke, K. C.: The spatiotemporal form of urban growth: measurement, analysis and modeling, Remote Sens. Environ., 86, 286-302, doi:10.1016/S00344257(03)00075-0, 2003.

Hsu, C.-H.: Hurricane Surge Flooding Damage Assessment and Web-Based Game Development to Support K12 Education for Understanding Climate Change Impact on Hurricane Surge Flooding Damage, Doctoral dissertation, Texas A \& M University, available at: http://hdl.handle.net/1969.1/153484 (last access: 18 August 2016), 2014.

Hurricanecity: The history with tropical systems in Panama City, Florida, available at: http://www.hurricanecity.com/city/ panamacity.htm, last access: 8 June 2015.

Inouye, C. E. N., de Sousa Jr., W. C., de Freitas, D. M., and Simões, E.: Modelling the spatial dynamics of urban growth and land use changes in the north coast of São Paulo, Brazil, Ocean Coast. Manage., 108, 147-157, doi:10.1016/j.ocecoaman.2014.12.016, 2015.

IPCC: Summary for Policymakers, in: Climate Change 2007: The Physical Science Basis. Contribution of Working Group I to the Fourth Assessment Report of the Intergovernmental Panel on Climate Change, edited by: Solomon, S., Qin, D., Manning, M., Chen, Z., Marquis, M., Averyt, K. B., Tignor, M., and Miller, H. L., Cambridge University Press, Cambridge, United Kingdom and New York, NY, USA, 2007.

IPCC: Summary for Policymakers, in: Climate Change 2013: The Physical Science Basis, Contribution of Working Group I to the Fifth Assessment Report of the Intergovernmental Panel on Climate Change, edited by: Stocker, T. F., Qin, D., Plattner, G.-K., Tignor, M., Allen, S. K., Boschung, J., Nauels, A., Xia, Y., Bex, V., and Midgley, P. M., Cambridge University Press, Cambridge, United Kingdom and New York, NY, USA, 2013.

Irish, J. L., Resio, D. T., and Cialone, M. A.: A surge response function approach to coastal hazard assessment. Part 2: Quantification of spatial attributes of response functions, Nat. Hazards, 51, 183205, 2009.

Jantz, C. A., Goetz, S. J., Donato, D., and Claggett, P.: Designing and implementing a regional urban modeling system using the 
SLEUTH cellular urban model, Comput. Environ. Urban, 34, 116, doi:10.1016/j.compenvurbsys.2009.08.003, 2010.

Knutson, T. R. and Tuleya, R. E.: Impact of $\mathrm{CO}_{2}$-induced warming on simulated hurricane intensity and precipitation: Sensitivity to the choice of climate model and convective parameterization, J. Climate, 17, 3477-3495, 2004

Leao, S., Bishop, I., and Evans, D.: Simulating Urban Growth in a Developing Nation's Region Using a Cellular AutomataBased Model, J. Urban Plan. Dev. Div., 130, 145-158, doi:10.1061/(ASCE)0733-9488(2004)130:3(145), 2004.

Leão, S., Bishop, I., and Evans, D.: Spatial-temporal model for demand and allocation of waste landfills in growing urban regions, Comput. Environ. Urban, 28, 353-385, doi:10.1016/S01989715(03)00043-7, 2004.

Lopez, R. and Hynes, H. P.: Sprawl In The 1990s: Measurement, Distribution, and Trends, Urban Aff. Rev., 38, 325-355, doi:10.1177/1078087402238805, 2003.

Ludy, J. and Kondolf, G. M.: Flood risk perception in lands "protected" by 100-year levees, Natural Hazards, 61, 829-842, doi:10.1007/s11069-011-0072-6, 2012.

Mahiny, A. S. and Gholamalifard, M.: Dynamic spatial modeling of urban growth through cellular automata in a GIS environment, Int. J. Environ. Res., 1, 272-279, 2007.

Nicholls, R. J. and Cazenave, A.: Sea-level rise and its impact on coastal zones, Science, 328, 1517-1520, 2010.

Onsted, J. and Clarke, K. C.: The inclusion of differentially assessed lands in urban growth model calibration: a comparison of two approaches using SLEUTH, Int. J. Geogr. Inf. Sci., 26, 881-898, doi:10.1080/13658816.2011.617305, 2012.

Onsted, J. A. and Chowdhury, R. R.: Does zoning matter? A comparative analysis of landscape change in Redland, Florida using cellular automata, Landscape Urban Plan., 121, 1-18, doi:10.1016/j.landurbplan.2013.09.007, 2014.

Onsted, J. A. and Clarke, K. C.: Forecasting Enrollment in Differential Assessment Programs Using Cellular Automata, Environ. Plann. B, 38, 829-849, doi:10.1068/b37010, 2011.

Project Gigalopolis: SLEUTH Applications, available at: http://www.ncgia.ucsb.edu/projects/gig/Repository/ SLEUTHapplications.html, last access: 26 December 2016.

Rafiee, R., Mahiny, A. S., Khorasani, N., Darvishsefat, A. A., and Danekar, A.: Simulating urban growth in Mashad City, Iran through the SLEUTH model (UGM), Cities, 26, 19-26, doi:10.1016/j.cities.2008.11.005, 2009.

Rienow, A. and Goetzke, R.: Supporting SLEUTH - Enhancing a cellular automaton with support vector machines for urban growth modeling, Comput. Environ. Urban, 49, 66-81, doi:10.1016/j.compenvurbsys.2014.05.001, 2015.

Runyan, R. C.: Small business in the face of crisis: Identifying barriers to recovery from a natural disaster, Journal of Contingencies and Crisis Management, 14, 12-26, 2006.
Sakieh, Y., Salmanmahiny, A., Jafarnezhad, J., Mehri, A., Kamyab, H., and Galdavi, S.: Evaluating the strategy of decentralized urban land-use planning in a developing region, Land Use Policy, 48, 534-551, doi:10.1016/j.landusepol.2015.07.004, 2015.

Santé, I., García, A. M., Miranda, D., and Crecente, R.: Cellular automata models for the simulation of real-world urban processes: A review and analysis, Landscape Urban Plan., 96, 108-122, doi:10.1016/j.landurbplan.2010.03.001, 2010.

Sekovski, I., Armaroli, C., Calabrese, L., Mancini, F., Stecchi, F., and Perini, L.: Coupling scenarios of urban growth and flood hazards along the Emilia-Romagna coast (Italy), Nat. Hazards Earth Syst. Sci., 15, 2331-2346, doi:10.5194/nhess-15-23312015, 2015.

Shows, E. W.: Florida's coastal setback line - an effort to regulate beachfront development, Coast. Manage., 4, 151-164, 1978.

Silva, E. A. and Clarke, K. C.: Calibration of the SLEUTH urban growth model for Lisbon and Porto, Portugal, Comput. Environ. Urban, 26, 525-552, doi:10.1016/S0198-9715(01)00014-X, 2002.

Song, J., Peng, Z.-R., Zhao, L., and Hsu, C.-H.: Developing a theoretical framework for integrated vulnerability of businesses to sea level rise, Nat. Hazards, 84, 1219-1239, doi:10.1007/s11069016-2483-x, 2016.

Udoh, I. E.: Robust hurricane surge response functions, Texas A\&M University, College Station, 2012.

US Census Bureau: TIGER/Line shapefiles and TIGER/Line Files, available at: http://www.census.gov/geo/maps-data/data/ tiger-line.html, 2016.

Vousdoukas, M. I., Voukouvalas, E., Mentaschi, L., Dottori, F., Giardino, A., Bouziotas, D., Bianchi, A., Salamon, P., and Feyen, L.: Developments in large-scale coastal flood hazard mapping, Nat. Hazards Earth Syst. Sci., 16, 1841-1853, doi:10.5194/nhess-161841-2016, 2016.

Wagner, D. F.: Cellular Automata and Geographic Information Systems, Environ. Plann. B, 24, 219-234, doi:10.1068/b240219, 1997.

Wu, X., Hu, Y., He, H. S., Bu, R., Onsted, J., and Xi, F.: Performance Evaluation of the SLEUTH Model in the Shenyang Metropolitan Area of Northeastern China, Environ. Model. Assess., 14, 221-230, doi:10.1007/s10666-008-9154-6, 2008.

Xiang, W.-N. and Clarke, K. C.: The Use of Scenarios in Land-Use Planning, Environ. Plann. B, 30, 885-909, doi:10.1068/b2945, 2003.

Yang, X. and Lo, C. P.: Modelling urban growth and landscape changes in the Atlanta metropolitan area, Int. J. Geogr. Inf. Sci., 17, 463-488, doi:10.1080/1365881031000086965, 2003.

Yue, W., Zhang, L., and Liu, Y.: Measuring sprawl in large Chinese cities along the Yangtze River via combined single and multidimensional metrics, Habitat Int., 57, 43-52, doi:10.1016/j.habitatint.2016.06.009, 2016. 